\title{
التظيم الانفعالي وعلاقته بدافع الإنجاز لدى عينة من طالبات جامعة أم القرى
}

\section{د. عبير محمد الصبان وأ. سماح عمر السلمي وأ. هبه عبد الحي الأنصاري}

مستخلص. التنظيم الانفعالي وعلاقته بدافع الإنجاز لاى عينة من طالبات جامعة أم القرى.






القرى بمختلف التخصصات. طبق عليهم مقياس التظيم الانفعالي لجروس وجون (2003) Gross \& John، ومقياس







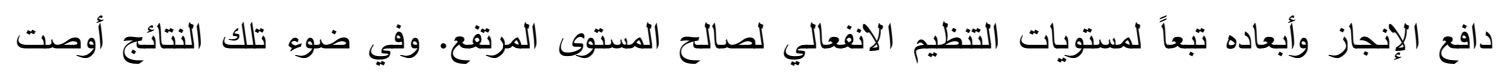
الدراسة بعدد من التوصيات.

تكاتفت الجهود للبحث في آلية تنظيم الانفعال التي بات من المعروف أنها تكمن وراء العديد من المشكلات ومنها المشكلات التعليمية والتربوية.

\section{المقدمـة}

على الرغم من الاهتمام القديم والمتجدد بدراسة الانفعالات في علم النفس، إلا أن البحث في مجال




لمتطلبات وظروف العصر الذي نعيش فيه فإن ذلك يحتاج قدرات عقلية ومهارات انفعالية من الفرد لحل المشكلات التي تواجهه ومواجهة العقبات التي تقف

$$
\text { في طريقه (سرحان، } 0 \text { 1 ب r). }
$$

حيث أن تتظيم الانفعال يعلمنا كيف نغير من أنماط تفكيرنا ومن طريقة نظرتنا إلى العالم ويولد في أنفسنا


نستطيع أن نحدد متى نغضب ومتى نخاف ومتى نهاه



$$
\text { نتعامل مع كل منها (مغربي، V... }
$$

وبذلك يمكن القول بأن تنظيم الانفعالات يؤثر في




أكدته دراسة Fried \& Chapman (2012) التي توصلت إلى وجود علاقة ارتباطيه موجبة بين مستوى تتظيم الانفعالات ودافعية الطلبة.




الانفعال وعلاقته بدافع الإنجاز لدى طالبات المرحلة







مشكلة الدراسة وتساؤلاتها تعد الانفعالات من العوامل المؤثرة في حياة وسلوكيات الأفراد، فالانفعالات الجامحة قد تؤدي إلى لى لقدي
إذ يعتبر تتظيم الانفعال من المفاهيم الجوهرية وجزء


المهارات الانفعالية والمعرفية والسلوكية التي تنظم وتسيطر على الخبرات والمواقف والتعبيرات الناتجة


ويتضمن تنظيم الانفعال القدرة على التعديل والتأثير في الانفعالات والمشاعر وتوجيهـا إلى الإنجان الإنهاز

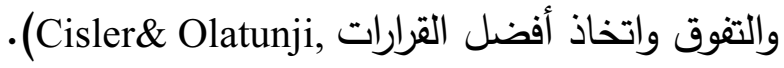
2012)


الانفعالية أساسية في فعالية التعلم، وأنها عنصر رئيسي لنجاح الطلاب في الدراسة، كما أن الافراد الذين لايهم القدرة على السيطرة على انفعالاتهم، وحسن إداراتها أكثر قدرة على التعلم والتفوق. وتعد الدافعية للإنجاز أحد العوامل المهمة التي تؤدي دوراً فاعلاً في تعلم المتعلم، حيث أن لها أهمية في زيادة انتباه الطالب واندماجه في الأنشطة التعليمية، ويرجع نجاحه وفشله إلى عوامل داخلية، وسيطرته على العوامل المؤثرة في إنجاز مهمة التعلم، كما لها دور في رفع مستوى أداء الطالب وانتاجيته في مختلف المجالات والأنشطة الدراسية التي يواجهها



وفي السياق نفسه يعد تتظيم الانفعال من العوامل التي تؤثر في دافعية الفرد للإنجاز، وتعتبر حلقة الوصل بين التنظيم العقلي والذاتي، وهذا ما ييرز تفاعل الجوانب المختلفة في شخصية الفرد، ونظراً 
بكل ما تتضمنه من مشاعر وانغعالات، وذلك لأن نجاح الإنسان في بيئته ترجمة لدافعية إنجازه بالصورة المطلوبة، وهي لا تتم بصورة فردية ولكن الإن العان من خلال التفاعل المباشر مع جميع الأفراد، فهم مشاعرنا ومشاعر الآخرين وترجمتها إلى سلوكيات الآناتيات ومواقف مفيدة لجميع الأطراف المشاركة في العملية الاجتماعية (Alen, 2005). لذلك يعتبر التظيم الجيد للانفعالات من العوامل

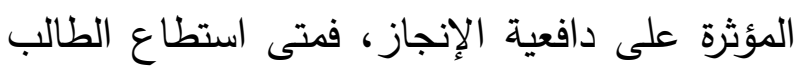
فهم وإدراك ذاته بسلبياتها وايجبياتها يوجه مشاعره وانفعالاته بالطريقة المناسبة لتعزيز أداءه وتحقيق


دافعية الإنجاز لديه.



\section{يمكن تحديد تساؤلات الدراسة كالتالي:} ا. ما هو مستوى التنظيم الانفعالي واستراتيجياته لاى عينة من طالبات جامعة أم القرى؟ الأفي r. هل توجد علاقة ذات دلالة إحصائية بين التتظيم التاليم الانفعالي ودافع الإنجاز لاى عينة من طالئ دالبات


r. هل توجد فروق ذات دلالة إحصائية بين


طالبات جامعة أم القرى تعزى لكستوى التتظيم




تهدف الدراسة الحالية إلى الكثف عن:
عدم التتظيم أو اضطراب العمليات النفسية وهي بدورها تؤثر على أداء وفعالية الفرد. وهذا ما أشار إلية فيل Vail (2005, 32 في أن الن النال هناك العديد من الأسباب التي تجعل بعض الأفراد




ينتابهم من انفعالات سلبية كالقلق، الخوف، عدم الفئ السعادة والغضب حيث يكون من أسباب الفشل عدم


الانفعالات السلبية وتوجيهها نحو الإنجاز و التثوق، أو عدم المعرفة بآلية التنظيم، فتنظيم الانفعالات الاتليات يمكن الفرد من تحقيق الأهداف التي يسعى إليها كما


الحياة المختلفة ولا سيما في الإنجال التعال التعليمي. ويعد دافع الإنجاز للطلبة من أكثر العوامل أهمية في التيال الععلية التزبوية حيث أنه يلعب دوراً حاسماً ومههاً في النجاح أو الفشل. فهي كما يرى موراي(1911)، •9 19) بأنها الرغبة المستمرة للسعي إلى النجاح


بكفاءة وأقل جها ووقت وبأفضل مستوى من التعلم. وهي حالة داخلية مرتبطة بمشاعر الفرد وتوجه نشاطه نحو التخطيط للعمل وتتفيذه بما يحقق لتقد


تعتبر دافعية الإنجاز دافعاً يتولد لاى الفرد يجعله في لهي موقف تنافسي (Albert, 2005) ومثل تلك الصفات لا يمكن التحلي بها وتتميتها دون فهم واعي لذاتتا 
ع.أهية الشريحة العمرية التي تتناولها الدراسة، المتمثلة في طالبات الجامعة، وهم ممن ينتمون إلى لى لهيه مرحلة المراهقة المتأخرة بضغوطها وتحدياتها، وتقلباتها الانفعالية، كما أنهن يكونون أكثر استهدافاً


أدائهن الأكاديمي وتوافقهن الجامعي. ه.إضافة بعض المعلومات والتفسيرات المرتبطة بالنتائج لنوع العلاقة بين تلك المتغيرات خصوصاً أن أن هناك قلة في الدراسات الأجنبية بصفة عامة لتصنة



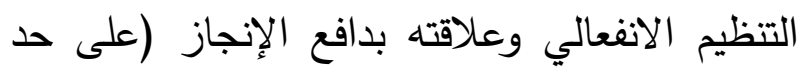


مصطلحات الدراسة

Gross \& التنظيم الانفعالي: عرفه جروس وجون Jأبانه "العمليات التي تحدث عندما يحاول الفرد أن يؤثر في نوع أو كمية الانفعال الذي لخي يخبره هو أو يخبره الآخرون من حوله وكيفية التعبير


ويعرف إجرائياً: بالدرجة الكلية التي تحصل عليها الطالبة على مقياس التنظيم الانفعالي المستخدم في هذه الدراسة اعداد (Gross \& John, 2003).

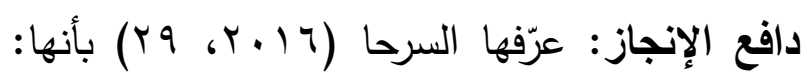
"تكوين افتراضي يتضمن الثعور المرتبط بالأداء في مواقف تتافسية تهدف لتحقيق معايير الامتياز
ا. مستوى التتظيم الانفعالي واستراتيجياته لاى عينة من طالبات جامعة أم القرى. r.نوع العلاقة بين التظظيم الانفعالي واستراتيجياته

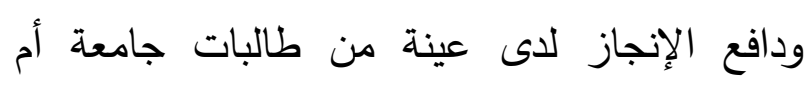


r. الفروق في دافع الإنجاز تبعاً لمستويات التنظيم الانفعالي لدى عينة من طالبات جامعة أم القرى. أهمية الدراسة زاد الاهتمام في السنوات الأخيرة بالتتظيم الانفعالي،




العوامل المؤثرة في الوظائف النفية والاجتماعية

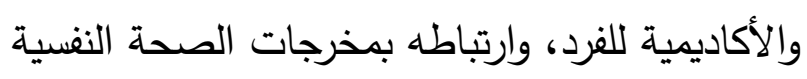
والجسمية، والإنجاز والأداء، فضلاً عن كونه مكوناً أساسياً من مكونات الذكاء الانفعالي.

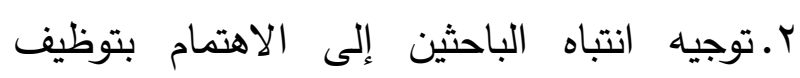


الدراسية لتحسين مستوى دافع الإنجاز لاى الطلبة وفقاً للتوجهات المعاصرة في علم النفس. r.الاستفادة من نتائج الدراسة في تصميم برامج إرشادية تسهم في تتمية تنظيم الانفعالات التكيفية،

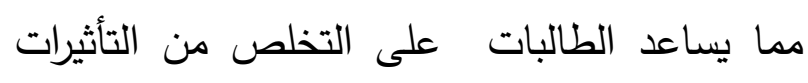
السلبية لحدة الانفعالات، وهذا بدوره ينعكس بشكل لئل

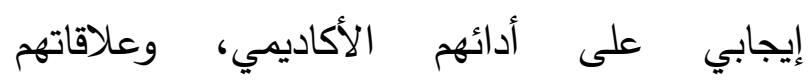
الاجتماعية، وتوافقهم وصحتهم الجسمية والنفسية بشكل عام. 
يعرف التظيم الانفعالي بأنه "تلك العملية المتصلة بالتعديل والتأثير على متى وكيف يتم التعبير عن الانفعالات الخاصة وكيف يتم معايشة تلك ملئ الانفعالات. ويشمل ذلك كل الانفعالات الشعورية واللاشعورية السلبية والموجبة على حد سواء" (Cisler, Olatunji, Feldner \& Forsyth, 2010 ,70) "وهو عملية تعديل وتأثير الفرد في نوع الانفعالات وشدتها واستمراريتها والتعبير عنها وكيفية معايشتها، ويتضمن تنظيم الانفعال استراتيجيتين هما :إعادة التقييم المعرفي، وقمع التعبير الانفعالي" (مظلوم، .$(9.4 .1 \mathrm{~V}$

ويرى جرانفسكي وكاريج (2007,142) Garnefski \& Kraaij "المهارات التي تحفظ توازن الفرد الانفعالي في علاقاته الانفعالية مع ذاته والآخرين، وتساعده في التحكم بعواطفه أثناء مواجهة أحداث التوتر



وقد ميزت سارني (1999) Saarni بين التظيم الذاتي وتنظيم الانفعالات، إذ تؤكد أن التظيم الذاتي هو قدرة الفرد على إدارة سلوكه، وأفكاره، ومشاعره بطرائق فعالة ومرنة في المواقف التي تعكس ظروفاً اجتماعية، وأخرى جسمية، ويساهم التنظيم الذاتي الأمثل في إحساس الفرد بالرضا، وبالكفاية الذاتية، وبالقدرة على التواصل مع الآخرين. وبالمقابل ترى سارني أن تتظيم الانفعالات يتمثل بقدرة الفرد على إدارة الخبرة الذاتية للانفعالات، وشدتها واستمراريتها،
وتعرف إجرائياً: بالدرجة التي تحصل عليها الطالبة على مقياس دافعية الإنجاز المستخدم في هذه الدراسة اعداد (السرحا، 7 ( • ب). حدود الدراسة

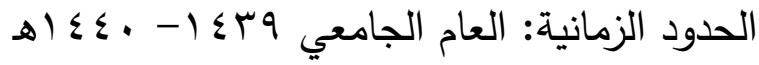
الحدود المكانية: جامعة أم القرى بمدينة مكة


الإطار النظري أولا: التنظيم الانفعالي Emotional Regulation الحياة الإنسانية حقل غني بالخبرات والأحداث السارة التي تصاحبها انفعالات إيجابية تشيطية تدفع الفرد للتفوق والإنجاز، الذي قد يتعرض لخبرات وظروف ضاغطة، وأحداث حياتية سالبة، تصاحبها انفعالات سلبية متباينة من حيث أنواعها وشدتها تعوق أداء الفرد وتترك تأثيراتها السلبية على صحته وشخصيته وعلاقاته الاجتماعية، ويحاول الفرد التخفيف من حدة الآثار السلبية للانفعالات من خلال إدارتها والتعبير عنها بشكل متوازن، وهو ما يعرف بتنظيم الانفعال (الضبع وشلبي، 0 ( إب). فقد ظهر ذلك المفهوم في مجال البحث النغسي لأول مرة عام • 199 وذلك عندما قدم Gross ذلك المفهوم من وجهة نظر علم النفس الاجتماعي مؤكداً على موه استخدام استراتيجيات التظيم الانفعالي لتعديل ديناميات الانفعال (الضبع وشلبي، 0 ـ ب). مفهوم التنظيم الانفعالي 


$$
\text { عبير محمد الصبان و سماح عمر السلمي و هبه عبد الحي الأنصاري }
$$

والتحكم في التعابير الانفعالية في مواقف التفاعل وفي واقع الأمر يعتبر مصطلح التظيم الانفعالي مختلفاً عن تلك المفاهيم وذلك باعتباره أحد أهم الاجتماعي. - الاعي مكونات الذكاء الانفعالي وهذا ما أكده سولفاي وماير عندما توصلا إلى مكونات الذكاء الانفعالي واعتبراه يتكون من ثلاث عمليات عقلية وهي (Vitello-

Cicciu, 2003, 30):

Appraising إدراك الانفعالات والتعبير عنها and expressing emotions

Regulating emotions r. تنظيم الانفعالات


emotions in adaptive ways كما يعتبر التنظيم الانفعالي أحد الأبعاد


(جولمان، ... . ب) خمسة أبعاد تعتبر أركان اساسية يتكون منها الذكاء الانفعالي وهي:



Cognitive Management البعد الثاني: إدارة الانفعالات of emotions

البعد الثالث: تنظيم الانفعالات Regulating of emotions البعد الرابع: التعاطف Empathy Social البعد الخامس: التواصل الاجتماعي لـاعي Communication هذا وتختلف مفاهيم تلك المصطلحات عن التظظيم الانفعالي فيما يشير إليه كل مفهوم فالضبط هيط وقد يكون تنظيم الانفعال بصورة شعورية أو غير شعورية. و يكون شعوري كاتخاذ قرار بتغيير مواضيع مزعجة، أو إخماد الضحك على لثعلى حركات طفل مثيرة للضحك، وقد يحدث بدون معرفة شعورية، كأن تصبح إعمال روتينية نمارسها بشكل




ألقاء نكتة لتهئه التوتر (Gross, 1999, 558). ومن الأفضل أن نفكر في التظظيم الانفعالي بمتصل يمتد من تتظيم شعوري يتطلب جهداً متحكم به إلى الى لعطي


2007, 11 مما سبق يمكن القول أن التنظيم الانفعالي يعبر عن جهود الفرد للسيطرة على حالة الاستثارة الانفعالية وإعادة توجيهها وتحسينها وتعديلها حتى يتمكن من الأداء المتكيف الذي يساعده على تحقيق أهدافه وتجاوز العقبات التي تواجهه. التتظيم الانفعالي والمصطلحات ذات العلاقة كثيراً ما يشيع الخلط بين مفهوم التنظيم الانفعالي ولئي


لذلك المفهوم ومن تلك المفاهيم الضبط الانفعالي، وإدارة الانفعال، الاتزان الانفعالي وهذا ما أثار إليه


كان يشار إليه في التراث النفسي بتلك المفاهيم. 
كيف يتعامل مع الآخرون بالانفعالات المختلفة، وكيف تتحول الانفعالات من مرحلة إلى أخرى". من خلال ما سبق ترى الباحثات أن مفهوم التنظيم الانفعالي يختلف عن مفاهيم الضبط الانفعالي،





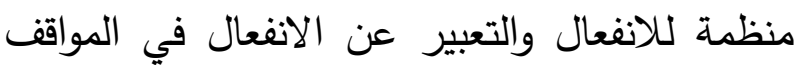
المناسبة له، ولكن الاستفادة من تلك الانفعالات وتوجيها إلى تحقيق الإنجاز والتفوق واتخاذ أفضل التصن






السلبية مثل الغضب. أبعاد التتظيم الانفعالي Gratz \& Roemer (2004) اشار جراتز ورومير الانعير إلى أن من أبعاد للتنظيم الانفعالي:

\section{:Emotional}


awareness لتوضيح المشاعر دون قهرها أو إنكارها أو تجنبها. ثانياً: القبول الانفعالي Emotional: acceptance الانفعالية السلبية لشعور ما على سبيل المثال الشعور بالذنب تجاه الثعور بالغضب.


flexibility استراتيجيات التنظيم الانفعالي بمرونة.
الانفعالي Emotional Control يشير إلى ضبط النفس والسيطرة عليها في المواقف التي تثير الانفعال والتقدير الإيجابي للذات بما يتضمن القدرة على حل المشكلات ومعالجتها ذاتيا والثعور بالاستقلالية والبعد عن الانانية (بقوش، 17 1.ب،

بينما الاتزان الانفعالي يعبر عن "مقدرة الفرد في السيطرة على انفعالاته والتحكم بها، وعدم افراطه في التهيج الانفعالي، أو عدم الانسياق وراء تأثيرات الأحداث الخارجية العابرة




وفي السياق نفسه عبر عثمان ورزق (Y....،




Emotions Management تشير إدارة الانفعالات إلى "القدرة على التحكم في الانفعالات السلبية، والسيطرة عليها واستدعاء الانفعالات الإيجابية بسهولة، وكسب الوقت للتحكم فيها وتحويلها إلى الى الحابط انفعالات إيجابية، وهزيمة القلق والاكتئاب وممارسة مهارات الحياة بفاعلية". بينما التظيم الانفعالي Emotional Regulation يشير إلى القدرة على "تتظيم الانفعالات والمشاعر، وتوجيهها إلى تحقيق الإنجاز والتنوق، واستعمال المشاعر والانفعالات في صنع أفضل القرارات، وفهج 
الانفعالية. ويفترض ذلك النموذج سلسلة من المراحل

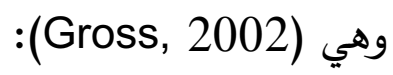

المرحلة الأولى: حيث يواجه الأفراد المواقف

التي يحتمل أن تولد استجابة انفعالية.

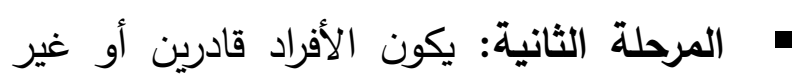

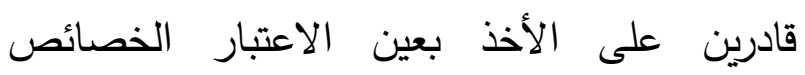
الانفعالية للموقف.

المرحلة الثالثة: يقوم الأفراد بتوليد تقييمات

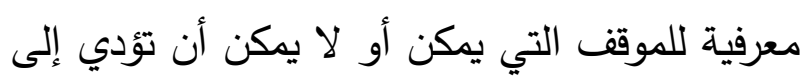
استجابة انفعالية. - الية

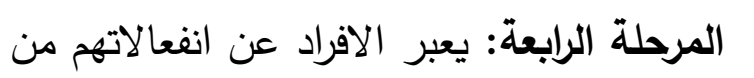


وحسب نموذج العمليات، فكل مرحلة من المراحل الأربعة لتوليد الانفعال يمكن أن تكون هدفاً لعملية التظيم (Koole, Dillen \&Sheppes, 2010). ويرى جروس Gross أن مكونات التنظيم الانفعالي تتضمن (Gross,1998):

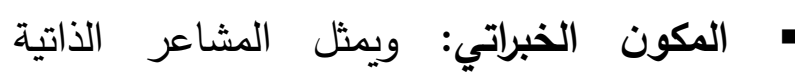
لانفعال الفرد وفقاً خبراته الحياتية.

• المكون السلوكي: ويمثل الاستجابات السلوكية. • المكون الفسيولوجي: ويمثل الاستجابات الفسيولوجية كضربات القلب وزيادة ضغط الدم. استراتيجيات التنظيم الانفعالي لاى جروس

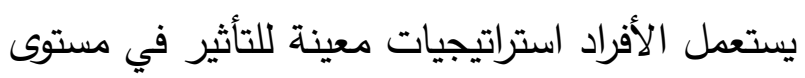
الاستجابة الانفعالية ليظهروا نمطاً معيناً من الانفعال

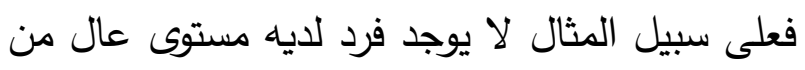

رابعاً: التسامح الانفعالي Emotional: تحمةtolerance تحقيق الأهداف ومنع السلوكيات المندفعة والتسامح في نفس الوقت (Han, 2009). خصائص التنظيم الانفعالي للتنظيم الانفعالي عدد من الخصائص يمكن تحديدها كالتالي ( Jazaieri, Morrison, :Goldin \& Gross, 2015) ا. مدى تأثير تتظيم الانفعال على شدة ومدة


r.تتظيم الانفعال يعتبر عملية واعية قصدية تتطلب مجهوداً، أو يمكن اعتبارها عملية تحدث بدون وعي.


سياقات محددة في ضوء الهدف التنظيمي للفرد لتحديد ما إذا كانت تكيفية، أو غير تكيفية. نماذج واستراتيجيات التظظيم الانفعالي هناك نماذج عديدة لتفسير التنظيم الانفعالي وسوف نذكر منها نموذج جروس Gross (1998)، ومن أشهر نماذج التنظيم الانفعالي، وفيما يلي توضيح



\section{نموذج جروس Gross (1998)}

وقد اقترح جروس Gross نموذج تنظيم الانفعالات، ويتضمن كل من الأساليب الشعورية والأساليب

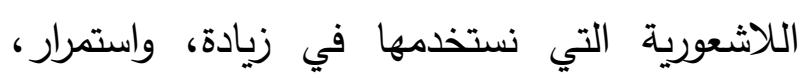
وخف واحد أو أكثر من مكونات الاستجابة 
أي يتحول الانتباه عن الشثيرات التي تثير مشاعر

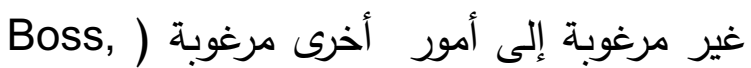
.(Pontier \& Treur 2007

Cognitive Change التغيير المعرفي ويقصد به انتقاء معنى معرفي للحدث ويهدف إلى تتظيم منخفض للانفعال. ويعتبر إعادة التقييم المعرفي Reappraisal أحد أهم أشكال التغيير المعرفي والذي يعني أن الفرد يعيد تقييم المعرفة للتخلص من الانفعال المحتمل حدوثه من ذلك لفي الموقف وخفض الأثر الانفعالي له ل (يعقوب، $\cdot(r+1)$

و يركز إعادة التقييم المعرفي على التاريخ الانفعالي للفرد وردوده الانفعالية حسب المواقف التي تعرض لترجي لها، وتحدث قبل الاستجابة الانفعالية حيث تقوم بالتخفيف من المشاعر السلبية وزيادة الإيجابية و تستعمل في علم النفس الإيجابي الذي يركز على التكيف والتفاؤل واختيار الجوانب الايجابية للوضع

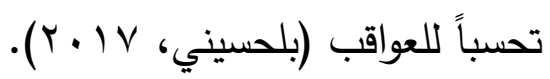

كما تؤكد تلك الاستراتيجية أن ردودنا الانفعالية نتيجة

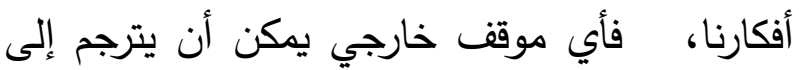

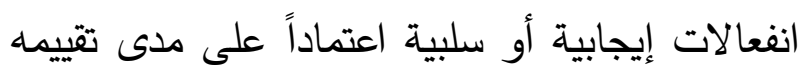


.(Koole et al., 2010) ثانياً: استراتيجية التركيز على الاستجابة Response Focused Strategies
الانفعال وفي الوقت نفسه لديه مستوى منخفض من

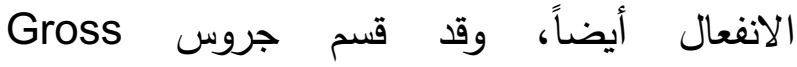
استراتيجيات التظظيم الانفعالي بناء على الوقت أثناء

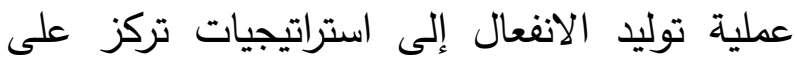

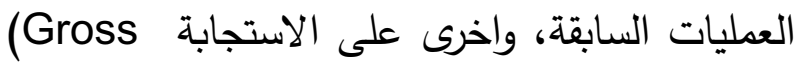
\& john, 2003) ويمكن توضيحها كالتالي: والهي أولاً: استراتيجية التركيز المسبق Antecedent Focused Strategies وهي التي يلجأ إليها الفرد في حالة الاستعداد

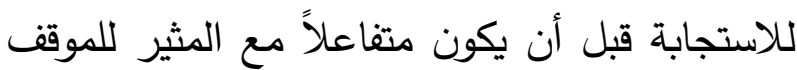
الانفعالي بشكل كلي وقد ميز جروس بين أربعة أنواع مختلفة لاستراتيجيات التركيز المسبق لتنيم الانفعال والتي يمكن أن تطبق في مواقف مختلفة في عملية توليد الانفعال (Gross, 2003) وهي: وني:

إختيار الموقف Situation Selection وتعني تجنب بعض الأفراد أو الأماكن أو الموضوعات، بهدف تنظيم الانفعال ( Putnam .(\& Silk, 2005

rituation Modification r. reع المديل حينما يتعدد الفرد موقف ليشعر بوضع انفعالي مختلف، فالشخص الذي يشاهد برنامج تلفزيوني

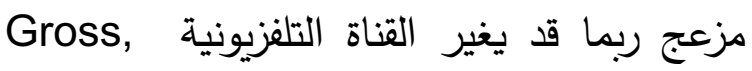
.(2007) r. نشر الانتباه Attention deployment وهو تغيير الانتباه بعيداً عن الموقف فقد يغلق الفرد عيناه حينما يشاهد عملية إطلاق رصاص ، الاهير 


$$
\text { عبير محمد الصبان و سماح عمر السلمي و هبه عبد الحي الأنصاري }
$$

إظهار ملامح وجه حيادية عنه عند تلقيه نقداً لاذعاً .(Gross\& Levenson,1993) دافع الإنجاز Achievement motivation يعتبر منتصف القرن العشرين نقطة البداية الحقيقية لاراسة الدافعية بشكل علمي ودقيق من حيث تحديد الصياغة الدقية للدفاهيم ودراستها إجرائياً، أو من ناحية مناهج البحث وأساليب القياس، حيث يعد موضوع الدافعية في علم النفس مهم على المستوى النظري أو التطبيقي (خليفة وعبد الله، (1 ـ ب). مفهوم دافع الإنجاز يعتبر الدافع للإنجاز أحد الدوافع الداخلية الفردية، على خلاف معظم الدوافع المماثلة (مثل الفضول والكفاءة) ويقتصر على الإنسان فقط، كما أنه كان موضوعاً لبحوث ودراسات مكثفة أكثر من الدوافع الأخرى (خليفة وعبد الله، 11 (Y). ويرجع استخدام مصطلح الدافع للإنجاز تاريخيا في ولاني


أعتبر الدافع للانجاز هي دافع تعويضي مستمد من خبرات مرحلة الطفولة، وليفن Levin الذي أثار لذلك المفهوم خلال دراسته مفهوم الطموح Aspiration الحاجة للإنجاز (عبد الخالق والنيال، (99 19 ). ورغم تلك البدايات المبكرة، فالفضل يعود إلى العالم النفسي الأمريكي هنري موراي، الذي يعتبر من أوائل الذين قدموا مفهوم دقيق للحاجة للإنجاز، باعتبارها أحد مكونات الشخصية (خليفة، . . . †).
وهي الاستراتيجية التي يلجأ الفرد لتطبيقها عندما

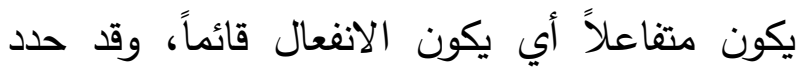

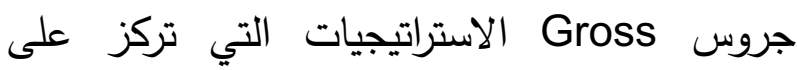
الاستجابة الانفعالية باستجابة واحدة فقط هي: Response تعديل أو قمع الاستجابة الانفعالية Modulation وتعني التركيز على الاستجابة وتطبق بعد حدوث الاستجابة الانفعالية وتدعى أيضاً بكبت التعبير وتعني أن الفرد يكف عن المضي في سلوكه التعبيري لانفعالاته في ذلك الموقف، أو أنه يخفي

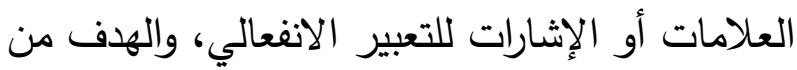


أو الانصياع للموقف (Gross, 2002). وتستعمل أثناء الموقف بهدف منع التعبير عن العواطف أواخفائها حتى لا تصل الانفعالات الداخلية للفرد الآخر، أي تغيير الاستجابة العاطفية بعد أن تم انشائها من الموقف، وتغيير الاستجابات السلوكية لتخفيض الحدة الانفعالية. وبالمقابل فإنه لا يمكن خفض الانفعال في ذلك الموقف ككل لان هذا يضر بالصحة النفسية للفرد ويشجع على لهور اضطرابات نفية انفعالية معينة مثل القلق والاكتئاب

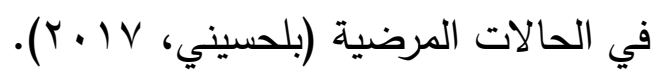
وقمع الاستجابة يستدل عليها من خلال عدم إظهار



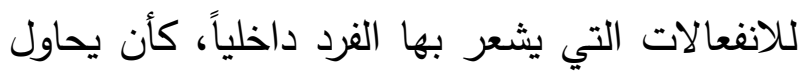


الفشل. فدافعية الإنجاز هي الناتج النهائي للعلاقة بين دوافع النجاح ودوافع تجنب الفشل والتفاعل فيما بينها، فالدافع للنجاح هو الذي يوجه سلوك الفرد للاستفادة من امكانيته وقدراته في تحقيق النجاح بكفاءة وفعالية، ويكون في صورة صعاب تواجه الفرد، اهتمامات متنوعة، الإحساس بالمقدرة، المنافسة، الاستقلال، وتكون هذه الدوافع بمثابة دوافع إقدام لدى الفرد(منصور ، التويجري، والفقي، $\cdot(r . .0$ وعلى العكس دوافع تجنب الفشل تستثير الفرد وتقلقه خلال قيامه بمعالجة المهام المختلفة، وتكون في صورة خوفه من الفشل، وضعف ثقته بقدراته ومعلوماته، وتمثل هذه الدوافع دوافع إحجام لدى الفرد (باهي وشلبي، 991 (1) ).

الخصائص الشخصية لذوي دافع الإنجاز المرتفع خلص كلٌ من الكناني والكندري (1999 (1) إلى عدد من السلوكيات التي يتصف بها ذوي دافعية الإنجاز

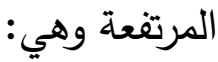
ا. يفضلون المهام التي تمدهم بمعلومات عن نتائج انجاززهم. r. يفضلون المهام متوسطة الصعوبة، أي التي يقترب احتمال النجاح في إنجازها من .0 ، عن المهام السهلة جداً التي يكون احتمال النجاح في إنجازها كبيراً 9 9 مثلاً.
ويمكن تعريف دافعية الإنجاز بأنها: "الرغبة في الإجادة والامتياز في تحقيق نتائج المهام التي يقوم بها الأفراد. وتنشأ تلك الدافعية من حاجات مثل السعي وراء التفوق، تحقيق الأهداف السامية، أو النجاح في المهام الصعبة" (الكناني والكندري، . (r) . 6994 كما يقصد بها: "استعداد الفرد لتحمل المسؤولية والسعي نحو التقوق لتحقيق أهداف معينة، والمثابرة للتغلب على العقبات والمشكلات التي قد تواجهه، والشعور بأهمية الزمن والتخطيط للمستقبل" (خليفة، .$(1) 6 r \cdot 7$ الاتجاه السلبي في دافع الإنجاز يجب للتمييز بين نوعين من الاتجاهات نحو الإنجاز الأول اتجاه إيجابي والآخر اتجاه سلبي، فقد لوحظ أن إنجاز الفرد قد لا يكون مرده حب النجاح فقط، وهو الاتجاه الإيجابي، وإنما قد يكون مرده أيضاً الخوف من عاقبة الفشل، وهو الاتجاه السلبي. وقد كشفت البحوث أن الاتجاه الإيجابي ينمو عندما تثيب الأم طفلها عند نجاحه وتكون استجابتها محايدة في حالة فثله، بينما ينمو الاتجاه السلبي للإنجاز في الحالات التي تستجيب الأم فيها بالحياء عند نجاح الطفل لكنها تقوم بعقابه في حالة الفشل

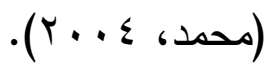

الدافع للنجاح والدافع لتجنب الفشل ليس كل ما نقوم به من أعمال مدفوع بالأمل في النجاح، إذ يكون أداؤنا أحياناً مصحوباً بالخوف من 
يميل للأداء والانهماك في انجاز السلوكيات. أما إذا حدث نوع من الفشل وتكونت بعض الخبرات السلبية، سوف ينشأ عنه دافع لتحاشي الفثل (خليفة وعبدالله، (r.) $(r)$

\section{Atkinson نظرية أتكنسون}

Atkinson and تمكن أتكنسون وفيثر 1966 Feather Expectation-Value Theory أساس أن النجاح يتبعه الشعور بالفخر والزهو، الإناز والفشل يتبعه الخجل والخزي. أضاف أتكنسون Atkinson الجديد للإنجاز حين تتاوله بعلاقات

$$
\text { رياضية (الزيات، ؟ . . ب). }
$$

فالدافع للإنجاز من وجهة نظر أتكنسون يعني

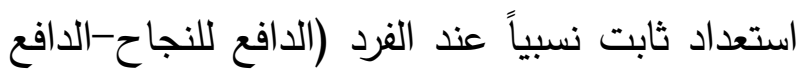

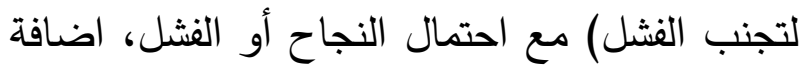
إلى قيمة الحافز الخارجي للنجاح أو الفشل (باهي الجئي

$$
\text { وشلبي، و (1991). }
$$

Atkinson ويتكون الدافع للإنجاز لاى أتكنسون

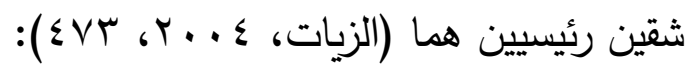
الثق الأول: المحددات الثخصية وهي استعدادات ثابتة نسبياً عند الفرد ولا تتغير بتغير المواقف وهي التعدات المختلفة .

الثق الثاني: المحددات البيئية ويعبر عنها بالفشل أو النجاح، وجاذبية الباعث الخارجي الموجب للنجاح


ذلك فإن تغيير ناتج الإنجاز عند الأفراد المختلفين r. يفضلون المهام التي توفر لهم قدراً كبيراً من


بالتحكم في نتائج جهدهم. ـ. يبذلون جهداً كبيراً في محاولة إنجاز وتحقيق ندان



ه. يثابرون في محاولاتهم لتحقيق نتائج أداء ناجحة، رغم ما يعترضهم من عقبات. يشعرون بالسعادة والرضا من مجرد تحقيق نتائج إنجاز ناجحة بصرف النظر عن أي عوائد خارجية. النظريات المفسرة لدافع الإنجاز McClelland نظرية ماكليلاند

بدأ الاهتمام بالدافع للإنجاز منذ أن نشر ماكليلاند

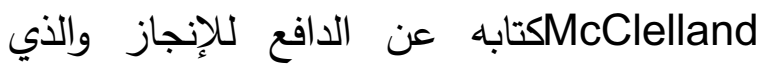

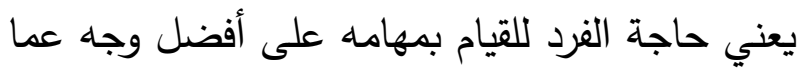
أنجز من قبل بكفاءة وأقل جهد، وأفضل نتيجة

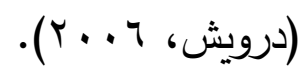

ولماكليلاندMcClelland (1975) إسهامات قيمة في الانتقال من تصور محدد لمفهوم الحاجة إلى تصور وجداني محدد بالتوقع. ويطلق على تصوره

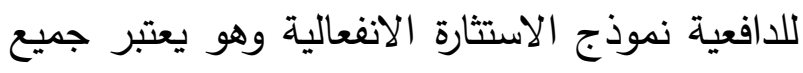
الدوافع متعلمة(الزيات، ع . . ب). يقوم تصور ماكليلاند McClelland لدافعية الإنجاز على تفسيره لحالة السعادة بالحاجة للإنجاز ، وأثشار

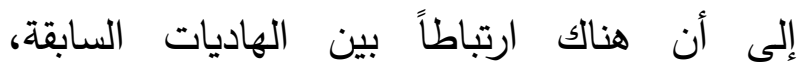

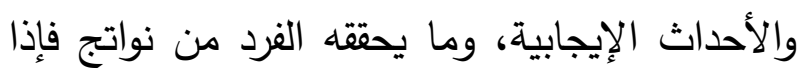
كانت مواقف الإنجاز الأولى للفرد ايجابية، فإن الفرد 
من خلال البحث والاطلاع على الدراسات ذات العلاقة بمتغيرات الدراسة الحالية وجدت دراسات

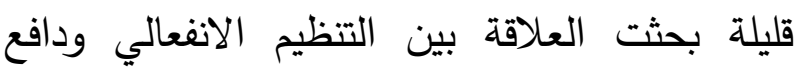

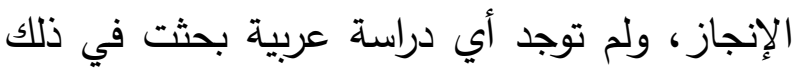

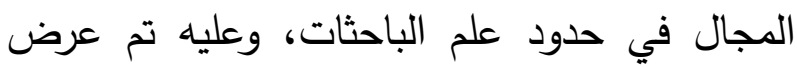
الدراسات السابقة من حيث الأقرب لعنوان الدراسة كالآتي:

Decuir- دراسة ديكوير - غنباي، التمان وشوتر Gunby, Aultman \& Schutz (2009) هدفت إلى التعرف على العلاقات التفاعلية بين

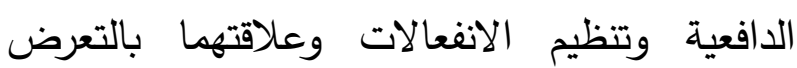




عشوائياً في عدد من الأقسام الأكاديمية، ولتحقيق

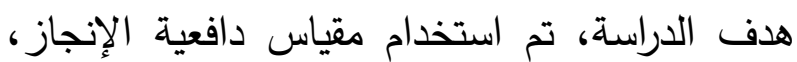
ومقياس تتظيم الانفعالات من إعداد الباحثين خلال

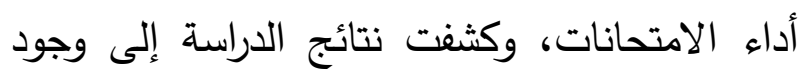

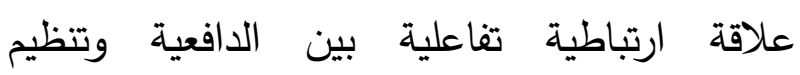
الانفعالات خلال أداء الامتحانات.

Fried \& (2012) كما هدفت دراسة فريد وشابمان


تنظيم الانفعالات وعلاقته بدافعية الطلبة والقدرة التنبؤية لكلا المتغيرين في تحديد الانخراط في مهام التعلم لدى طلبة المرحلة الإعدادية، وقد تكونت عينة

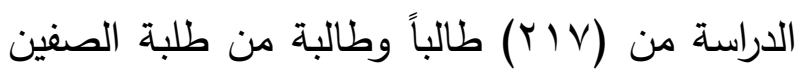
السابع والثامن من طلاب المرحلة المتوسطة تم
يرجع إلى المحددات الثخصية، وعند الفرد نفسه من موقف لآخر برجع إلى الى المحددات البيئة حيث

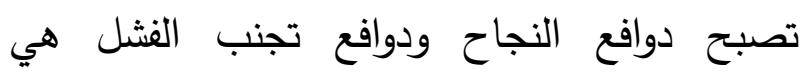
المحددات الأساسية لدافعية الإنجاز . لاحظ أتكنسون وفيثر 1966 Atkinson and Feather

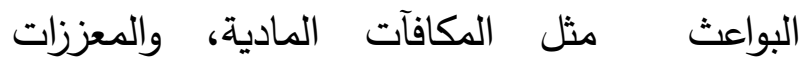
الاجتماعية، والمركز الأدبي والاجتماعي المرتبط بالهدف المنجز. وأُطلق عليها البواعث الخارجية

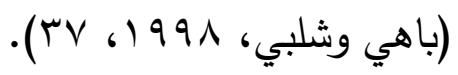
نظرية العزو السببي

تهتم هذه النظرية بكيفية إدراك الفرد لأسباب سلوكه،

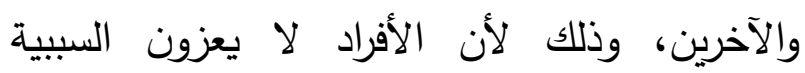
للفاعل، ولكن للبيئة، فالمعزيات السببية هي التي لهني تحدد مشاعر واتجاه وسلوك الافراد نحو أنفسهم


ويرتبط العزو السببي باعتقاد الفرد في أي العوامل



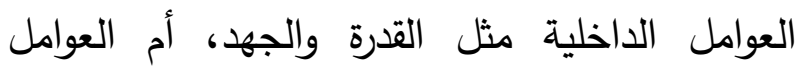
الخارجية التي تتعلق بالظروف أم صعوبة المهمة، تلك التفسيرات إذا اتسمت بالثبات النسبي مع تكرار

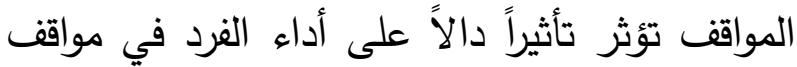
الإنجاز اللاحقة حيث يتباين هذا التأثير بتباين تلك لكون

$$
\text { ثانياً: الدراسات (باهي وشلبي، } 991 \text { (1) ). }
$$


إحصائية في التظيم الانفعالي تعزى للجنس، التخصص، والصف الدراسي.

Al, في حين هدفت دراسة البدارين (2016) Badareen والمشتركة لاستراتيجيات التنظيم المعرفي الانفعالي في التحصيل الأكاديمي لاى عينة من طلبة الجامعة لإسيات

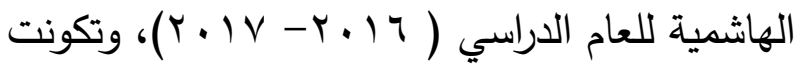
عينة الدراسة من (†^ґ) طالب وطالبة من الطلبة المسجلين بمسار مدخل لعلم النفس، ولتحقيق أهداف الدراسة تم استخدام مقياس استراتيجيات التتظيم المعرفي الانفعالي الذي طوره جارنفسكي وآخرون Garnefski et al.2001 التراكمي (GPA) ، وأظهرت نتائج الدراسة وجود

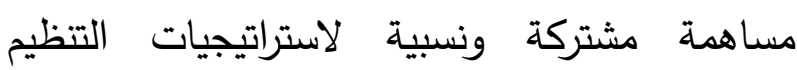
المعرفي الانفعالي في التحصيل الأكاديمي. كما اهتمت دراسة دورا Dora Do12 بحث علاقة كل من ضبط النفس، والتنظيم الانفعالي، الاجترار، والجنس بقلق الامتحان والتعرف على مدى إسهام هذه المتغيرات في التتبؤ بقلق الامتحان، وتكونت عينة الدراسة من (1/1) من طلاب السنة التحضيرية في إحدى الجامعات الخاصة بمدينة أنقرة، وتم تطبيق قائمة قلق الامتحان إعداد Spielberger 1980 ومقياس التنظيم الانفعالي إعداد 2003 Gross \& John والذي يقيس استراتيجيتي (الكتمان-إعادة التقييم المعرفي)، ومقياس الاستجابة الاجتراريا،، ومقياس ضبط النفس،
اختيارهم بطريقة عشوائية، ولتحقيق هدف الدراسة تم تطوير مقياس تنظيم الانفعالات ومقياس للدافعية من

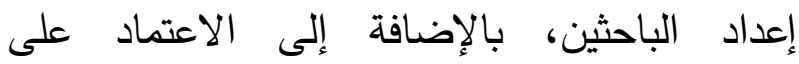

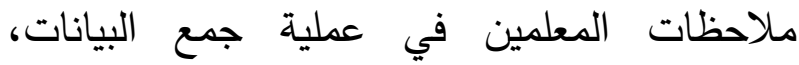
وكثفت نتائج الدراسة أن مستوى تنظيم الانفعالات

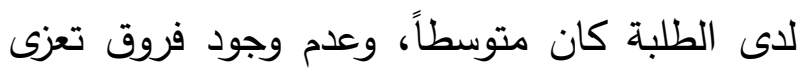
إلى الصف والجنس في مستوى تنظيم الانفعالات، ووجود علاقة ارتباطية موجبة بين مستوى تنظيم

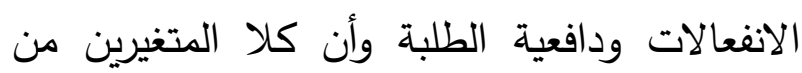
عوامل التنبؤ الدالة احصائياً في انخراط الطلبة في

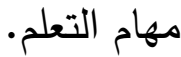
وفي السياق نفسه هدفت دراسة عياش (T + ب) إلى دراسة التنظيم الانفعالي للى طلبة الجامعة وفق

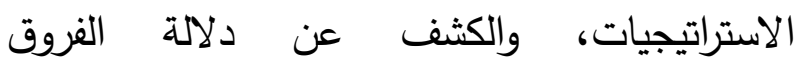
الإحصائية للتظيم الانفعالي واستراتيجياته تبعاً لبعض المتغيرات كالجنس، التخصص (العلمي، الإنساني) والصف الدراسي (الأول، الثاني، الثالث،

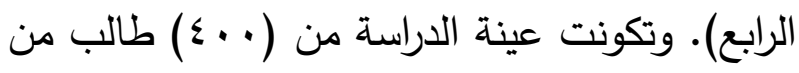
طلبة جامعة بغداد للدراسات الصباحية للعام الدراسي

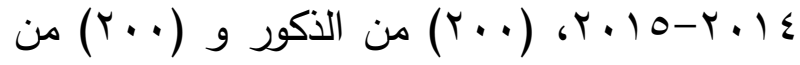

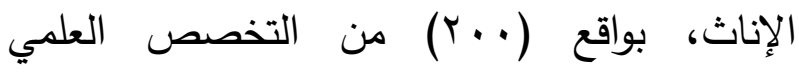

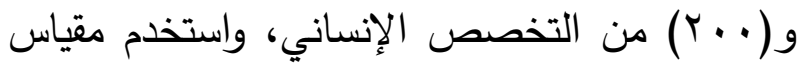
التنظيم الانفعالي لديفيد 2012 David ، وأظهرت النتائج أن طلبة الجامعة يتمتعون بمستوى جيد من لائن التنظيم الانفعالي، ولا توجد فروق ذات دلالة 
الاختبار، وتكونت العينة من (v (0) طالبا وطالبة من طلبة جامعة اليرموك ، وتم استخدم مقياس

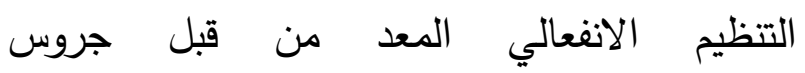
وجون Gross \& John (2003)، وأظهرت نتائج الدراسة أن مستوى التتظيم الانفعالي جيد لدى العينة، كما تم التوصل إلى وجود علاقة عكسية بين التنظيم الانفعالي وقلق الاختبار، ووجود فروق ذات دلالة إحصائية في التظيم الانفعالي في بعد إعادة التقييم تعزى للجنس لصالح الإناث، بينما لا توجد فروق في التنظيم الانفعالي تعزى للمستوى الدراسي ونوع الكلية.


الإستراتيجيات المعرفية لتنظيم الانفعال الشائعة لدى المراهقين والراشدين، والكشف عن الفروق بين المراهقين والراشدين في الإستراتيجيات المعرفية لتظيم الانفعال. ومعرفة علاقة تلك الاستراتيجيات بحالة وسمة القلق والاكتئاب لديهج، وتكونت عينة الدراسة من (r (T) طالباً وطالبة بالفرقة الثانية بكلية التربية بالعريش- جامعة قناة السويس بواقع (عابه)

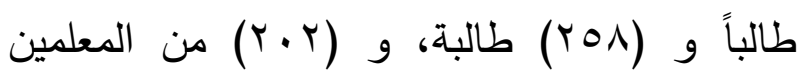
والمعلمات بواقع (r • (1) ذكور و( · · (1) من الإناث الملتحقين بالدبلوم العام في التربية، واستخدم مقياس

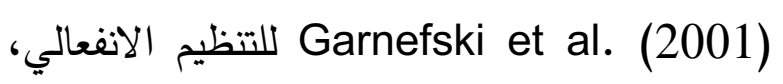
وتم التوصل الى عدة نتائج منها أن استراتيجية إعادة التقييم الإيجابي تحتل الترتيب الأول في الاستخدام لدى المراهقين، والترتيب السادس لدى الإي
ومن أهم النتائج التي أسفرت عنها الدراسة وجود ارتباط سالب ودال بين استراتيجية إعادة التقييم المعرفي وقلق الامتحان، أي أن الطلاب الذين يستخدمون استراتيجية إعادة التقييم المعرفي لديهم مستوى منخفض من قلق الامتحان، ووجود ارتباط موجب بين قلق الامتحان واستراتيجية الكتمان.

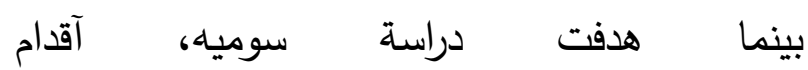
Som'eh, Aghdam \& و (2015) ونوسورت Nosort الانفعالي المعرفية في التتبؤ بقلق الامتحان، وطبقت الدراسة على ( . . . طالب من طلاب الجامعة تم اختيارهم بطريقة عشوائية، وتم استخدام مقياس التنظيم الانفعالي المعرفي من إعداد (2001) Garnefski, Kraaij \& Spinhoven قلق الامتحان من إعداد (1980) Sarason (1900) وأوضحت نتائج الدراسة وجود علاقة ارتباطية دالة احصائياً بين استراتيجيات تتظيم الانفعالات وقلق الامتحان وإلى إمكانية التتبؤ بقلق الامتحان من خلال بعض استراتيجيات التتظيم الانفعالي المعرفية وهي (إعادة التركيز الإيجابي، استراتيجية تركيز التفكير ، الاجترار واستراتيجية التفكير الكارثي). كذلك هدفت دراسة البراهمة (Y I . r) إلى الكشف عن مستوى التظيم الانفعالي ومستوى قلق الاختبار لاى طلبة الجامعة ومدى اختلافهما باختلاف الجنس الجس ونوع الكلية والمستوى الدراسي، واستقصاء العلاقة الارتباطية بين كل من التظيم الانفعالي وقلق 


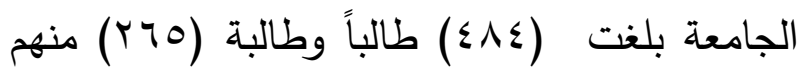
ذكور و (Y/9) إناث، باستخدام مقياس التنظيم

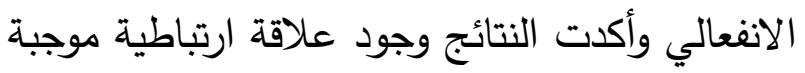
دالة بين استراتيجيات لوم الذات، والاجترار،

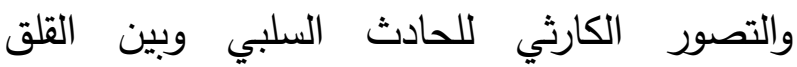

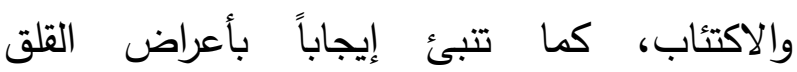
والاكتئاب، ووجود علاقة ارتباطية سالبة دالة بين استراتيجيات إعادة التركيز الإيجابي، والتخطيط،

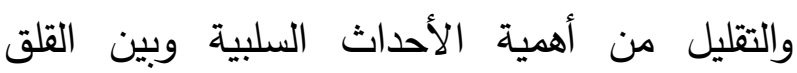
والاكتئاب، كما تتبئ سلباً بأعراض التقلق والاكتئاب، بالإضافة إلى عدم وجود علاقات دالة دالة بلين استراتيجيات التقبل، وإعادة التقييم الإيجابي، ولوم الآخرين وبين القلق والاكتئاب. التعليق على الدراسات السابقة بعد استعراض الدراسات ذات العلاقة بالتنظيم الانفعالي يتضح تباين تلك الدراسات واختلافها في تتاولها للتظيم الانفعالي من عدة نواحي يمكن توضيحها كالتالي: طبيعة المتغيرات من خلال الاطلاع على أدبيات الدراسات السابقة تبين ندرة وقلة الدراسات التي ربطت موضوع التنظيم

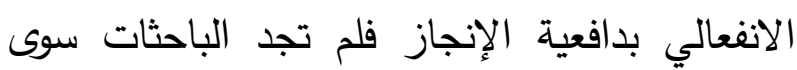

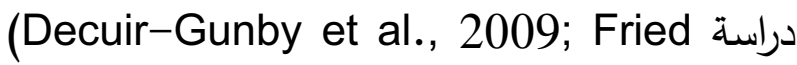
د \& Chapman, 2012). الدراسات متغير التتظيم الانفعالي وقلق الامتحان كما في دراسة (Som'eh et al., Dora, 2012)
الراشدين، توجد فروق ذات دلالة إحصائية بين المراهقين والراشدين لصالح المراهقين في استراتيجية دادين

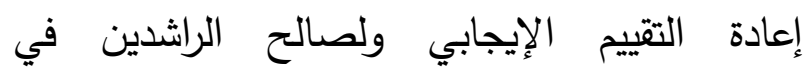
استراتيجية التخطيط، كما توجد علاقة ارتباطيه موجبة دالة إحصائياً بين استراتيجيات لوم الذات،

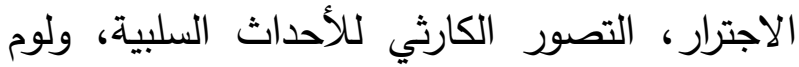
الآخرين وبين حالة القلق، سمة القلق، والاكتئاب

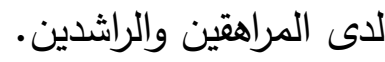

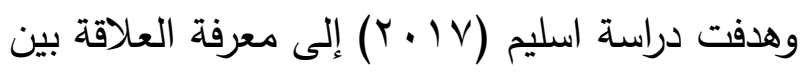

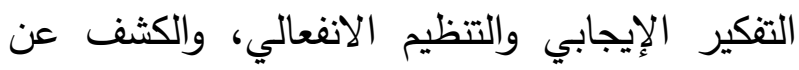
الفروق في مستوى التفكير الإيجابي والتتظيم الانفعالي تبعاً لمتغير (الجنس، مستوى دخل الأسرة، الجامعة، المعدل التراكمي)، وتكونت عينة الدراسة من (ع بr) من خريجي الجامعات الفلسطينية بغزة

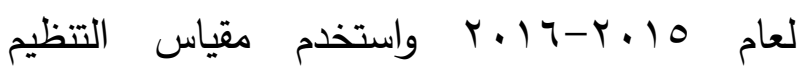
الانفعالي من إعداد الباحث، وتم التوصل إلى وجود مستوى مرتفع من التظيم الانفعالي لدى الطلبة البالي الخريجين، ووجود علاقة ارتباطية موجبة بين التفكير

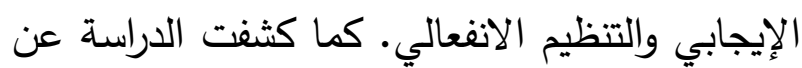
عدم وجود فروق في التظظيم الانفعالي تبعاً للجنس الإنس

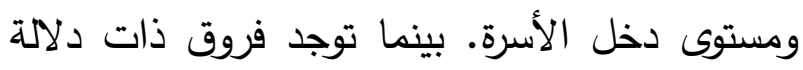
إحصائية في التنظيم الانفعالي تبعاً للمعدل التراكمي لتوني وذلك لصالح الخريجين ذوي المعدل الممتاز . كما درس عمران Omran (2011) العلاقة بين الاستراتيجيات المعرفية لتنظيم الانفعال وبين القلق دمرنق

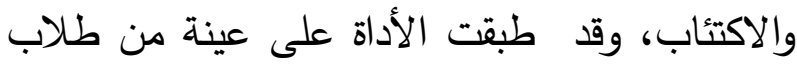




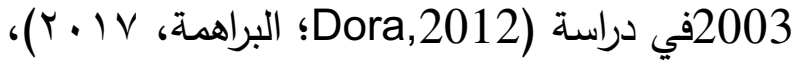

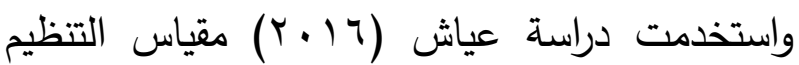
الانفعالي لايفيد 2012 David. النتائج التي توصلت إليها الدراسات

اتفقت العديد من الدراسات على وجود علاقة ارتباطية بين تتظيم الانفعالات وعدد من المتغيرات، (Decuir-Gunby et al., يث توصلت دراسة 2009; Fried \& Chapman, 2012) علاقة ارتباطية موجبة بين الدافعية وتتظيم (Dora, 2012; الانفعالات، وتوصلت دراستة (Y. Pom'eh et al., 2015) وجود علاقة دالة إحصائياً بين استراتيجيات تتظيم الانفعالات وقلق الامتحان، وكذلك توصلت دراسة البدارين (2016) Al, Badareen مساهمة مشتركة ونسبية لاستراتيجيات التتظيم المعرفي الانفعالي في التحصيل الأكاديمي،

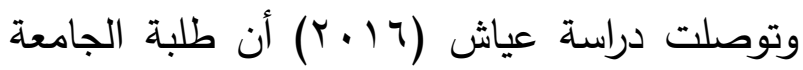
يتمتعون بمستوى جيد من التتظيم الانفعالي.

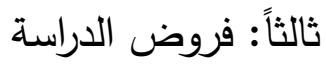
1. توجد مستويات مختلفة للتظيم الانفعالي واستراتيجياته لاى عينة من طالبات جامعة أم القرى. r. لا توجد علاقة ذات دلالة إحصائية بين التتظيم الانفعالي واستراتيجياته ودافع الإنجاز لاى عينة من لن


r. لا توجد فروق ذات دلالة إحصائية بين متوسطات الدرجات الكلية لدافع الإنجاز لدى عينة
2015; ودراسة البراهمة (Y V V V)، وبعضها بحثت عن مستوى التتظيم الانفعالي والاستراتيجيات الأكثر

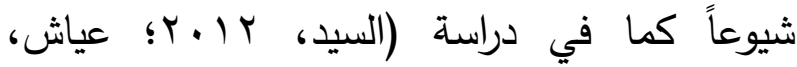

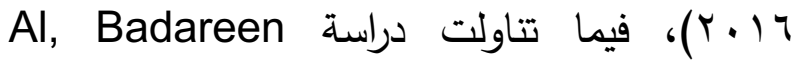
(2016) علاقة التظيم الانفعالي بالتحصيل

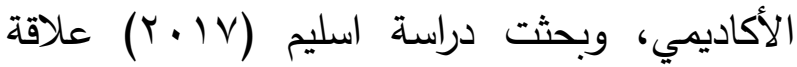
التتظيم الانفعالي بالتفكير الإيجابي، كما تم ربط

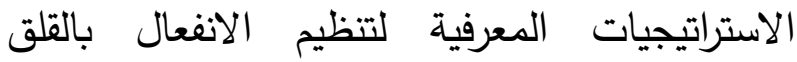
والاكتئاب في دراسة (2011) Omran. العينة المطبق عليها

تباينت الدراسات من حيث العينة المطبق عليها، فهناك دراسات طبقت على طلبة الجامعة كدراسة (Decuir-Gunby et al., 2009; Omran, 2011; Dora, 2012; Som'eh et., 2015; (Al, Badareen, 2016)

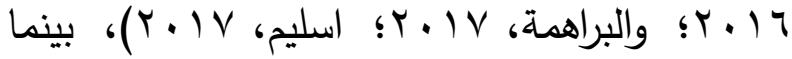
Fried \& Chapman أجريت دراسة فريد وشابمان (2012)على طلاب المرحلة المتوسطة، ودراسة

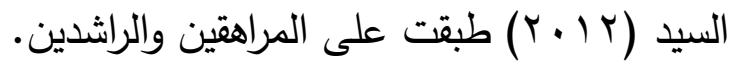
الأدوات المستخدمة اختلفت الأدوات المستخدمة في كل دراسة وذلك تبعاً للعينة المطبق عليها واختلاف البيئة فيها، فقد Garnefski et استخدم مقياس جارنغسكي وآخرون

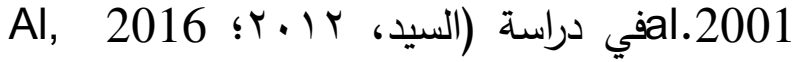
بينما (Som'eh et al, 2015 ؛Badareen, Gross \& John استخدم مقياس جروس وجون 
تross \& تم استخدام مقياس جروس وجون John (2003) تكون من (•(1) عبارات موزعة على استراتيجيتين وهي إعادة التقييم وتضم (؟) عبارات، والكبت وتضم

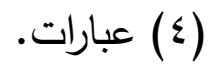
口 الخصائص السيكومترية للمقياس أولاً: الصدق تم حساب الصدق بطريقة الاتساق الداخلي واستخراج قيم معاملات ارتباط كل فقرة مع الدرجة الكلية للمجال الذي تتمي اليه، وجميعها تجاوزت (5 بـ, •).

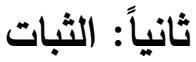

تم حساب الثبات باستخدام معامل ارتباط بيرسون

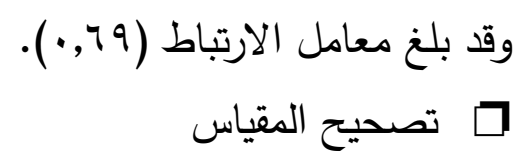
وللإجابة على الفقرات يختار المفحوص من سبع بدائل وفق تدريج ليكرت السباعي وهي اتقق بشدة

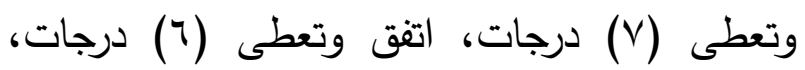

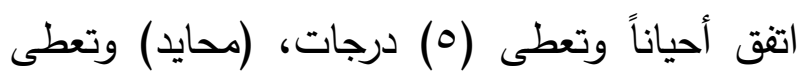
(§) درجات، أرفض أحياناً وتعطى (r) درجات،

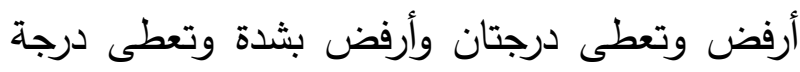

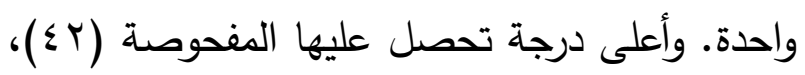
بينما أدنى درجة (؟). ويتم الحكم على مستوى درجه التنظيم الانفعالي حسب المعيار الآتي كما هو لهابه

$$
\text { موضح في جدول (1). }
$$

من طالبات جامعة أم القرى تبعاً لمستويات التتظيم الانفعالي. منهج الدراسة

استخدمت الدراسة في ضوء أهدافها وتساؤلاتها وفروضها المنهج الوصفي الارتباطي و والسببي الهقارن، بهدف الكثف عن العلاقة بين التتظيم الانفعالي ودافع الإنجاز لاى الطالبات. 口 مجتمع الدراسة يتحدد مجتمع الدراسة من جميع طالبات جامعة أم القرى لمختلف الكليات والتخصصات بمرحلة

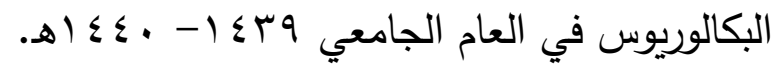
口 ع ع الدراسة 1. العينة الاستطلاعية: تكونت من (• (7) طالبة من طالبات جامعة أم القرى في مرحلة البكالوريوس

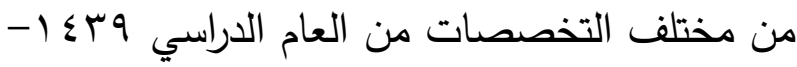
.ه ( ) r. العينة الأساسية: أجريت الدراسة على عينة عشوائية تكونت من (• (1) طالبة، وتم استبعاد (T) استبانة لعدم إجابة العينة على جميع فقرات المقياس أو الإجابة عليها بطريقة عشوائية، وأصبح العدد بعد ذلك (

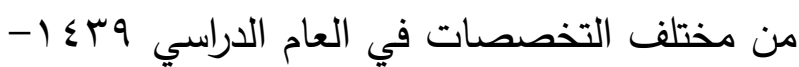
.ه $) \leqslant$. 口 أدوات الدراسة أولاً: مقياس التنظيم الانفعالي 


\begin{tabular}{|c|c|}
\hline مستوى التنظيم الانفعالي & فئة الأوساط الحسابية \\
\hline منخفض & من (1-r) \\
\hline متوسط & من (• (, r- \\
\hline مرتفع & من ( \\
\hline
\end{tabular}

كل بعد والدرجة الكلية للمقياس كما هو موضح في جدول (Y) ، وحساب ارتباط فقرات البعد وبالدرجة

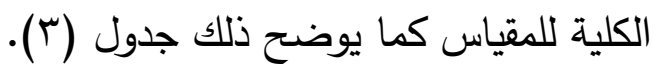

口 صدق وثبات المقياس في الدراسة الحالية أولاً: الصدق أصدق

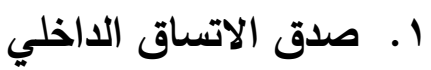
تم حساب صدق الاتساق الداخلي لمقياس التنظيم الانفعالي عن طريق حساب قيم معاملات ارتباط بين

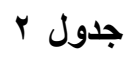

قيم معاملات الارتباط بين أبعاد مقياس التنظيم الانفعالي والدرجة الكلية (ن= . . ج)

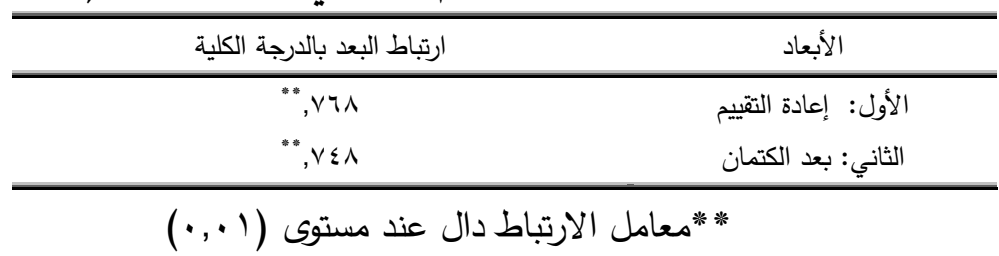

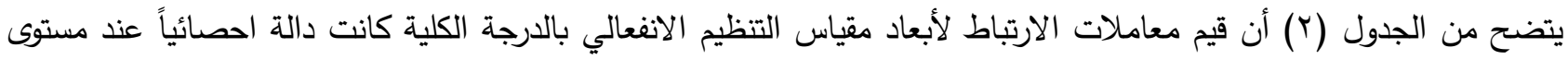
(1) (ب) وهي معاملات ارتباط جيدة.

\section{جدول باليه}

قيم معاملات الارتباط بين درجة كل فقرة والبعد الذى تنثى جدول إليه والدرجة الكلية لمقياس التنظيم الانفعالي (ن = . ؟) الأبعاد

\begin{tabular}{|c|c|c|c|c|c|}
\hline \multicolumn{3}{|c|}{ بعد الكتمان } & \multicolumn{3}{|c|}{ بعد إعادة التقييم } \\
\hline الارتباط بالدرجة & بالبعد & الفقرة & الارتباط بالدرجة الكلية & الارتباط بالبعد & الفقرة \\
\hline$", r \wedge \Lambda$ & "ט & $r$ & " ", हrr & " "TAY & 1 \\
\hline "* $\leqslant$ ४ & $" *$ " $\leqslant 94$ & $\varepsilon$ & "or & "* , VIr & r \\
\hline ",ort & דיזו, " & 1 & $" *, \leq 0 \leq$ & $" *, 7.1$ & 0 \\
\hline$"$ ", $\leqslant \wedge 4$ & $*$ & $\wedge$ & $" *, r \Lambda \Lambda$ & ",orl & v \\
\hline$" *, r q$. & ",ov. & 1. & $", 09 \varepsilon$ & $" *, v \leq 0$ & 9 \\
\hline
\end{tabular}

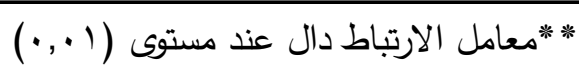




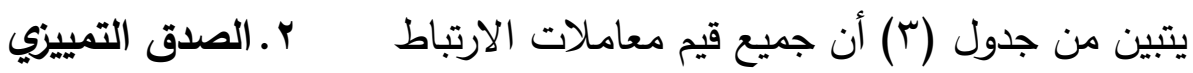

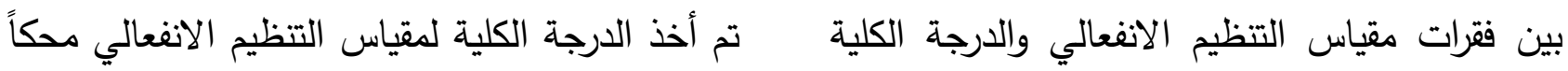

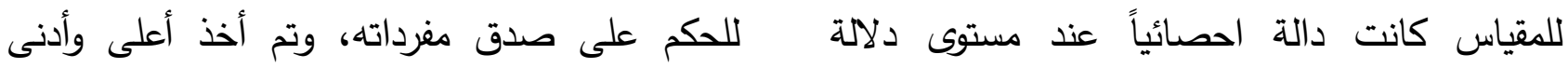

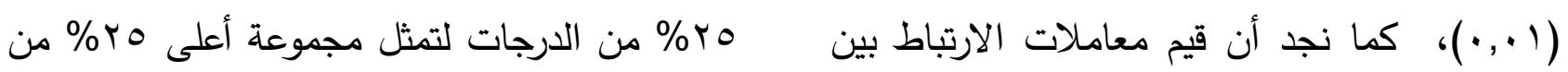

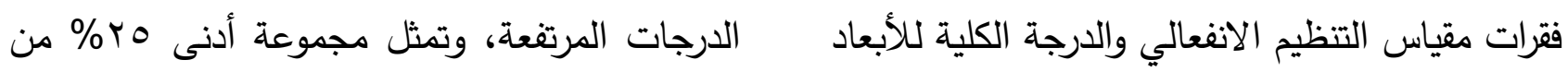
التي تتنمي إليها كانت دالة لجميع فقرات المقياس الدرجات المنخفضة في التنظيم الانفعالي، وباستخدام

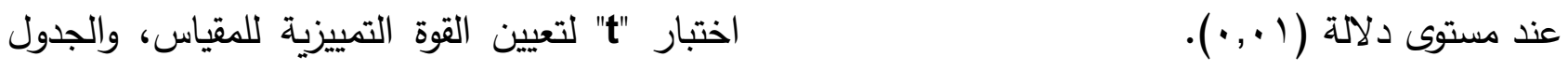

$$
\text { ( ) (ع) يوضح النتائج. }
$$

\section{جدول ؛}

قيمة (ت) لدلالة الفروق بين متوسطات المجموعات الطرفية (الإباعي الأعلى والإرياعي الأدنى) لمقياس التنظيم الانفعالي (ب)

\begin{tabular}{|c|c|c|c|c|c|c|c|}
\hline الدلالة & قيمة (t) & الدرجة & المعياري & المتوسط & العينة & الإرباعيات & المتغير \\
\hline.,$\cdot 1$ & T, זYA & 70 & $\begin{array}{l}\cdot, \Upsilon \wedge Y \\
., 9 \wedge \Lambda\end{array}$ & $\begin{array}{l}7,10 \\
r, 91\end{array}$ & $\begin{array}{l}r \mu \\
r \varepsilon\end{array}$ & الإرباعي الأعلى & التنظيم الانفعالي \\
\hline
\end{tabular}

يتضح من الجدول السابق أن قيمة "ت" للفرق ين متوسطات المجموعات الطرفية (الإرباعي الأعلى -الإرباعي الأدنى) داله

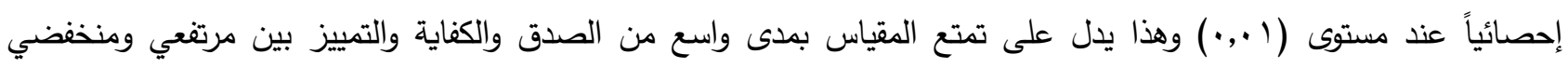
التنظيم الانفعالي. ثانياً: الثبات تُّ جساب):ثبات مقياس التنظيم الانفعالي بطريقة ألفا كرونباخ وطريقة التجزئة النصفية كما هو موضح في جدول قيم معاملات الثبات بطريقتي ألفا كرونباخ والتجزئة النصفية لمقياس التنظيم الانفعالي (ن= . • ج)

\begin{tabular}{|c|c|c|}
\hline \multicolumn{2}{|c|}{ التجزئة النصفية } & \multirow{2}{*}{ كرونباخ ألفا } \\
\hline (معادلة جتمان) & (سبيرمان براون) & \\
\hline & & \\
\hline
\end{tabular}

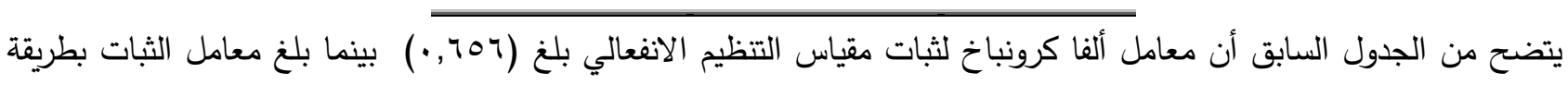

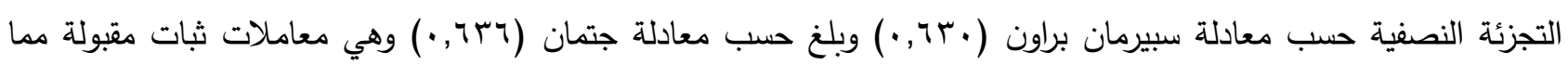
يعني أن المقياس يتمتع بدرجة ثبات جيدة. 
يستجيب المفحوص على كل فقرة من فقرات المقياس

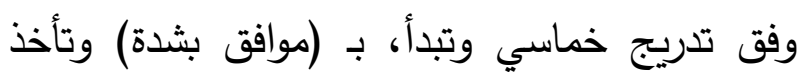

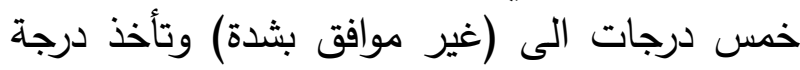

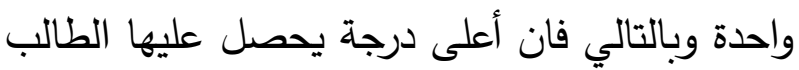

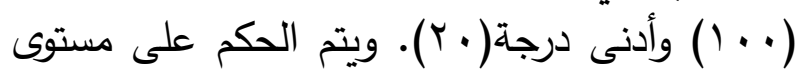
دافعية الإنجاز حسب المعيار الآتي كما هو موضح

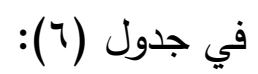$$
\text { جدول } 1
$$

مستوى دافع الإنجاز حسب المتوسط

\begin{tabular}{|c|c|}
\hline مستوى دافعية الانجاز & فئة الأوساط الحسابية \\
\hline منذفض & من (1- \\
\hline متوسط & من (. (r, \\
\hline مرتفع & من (., (0-r,0) \\
\hline
\end{tabular}

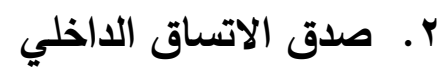

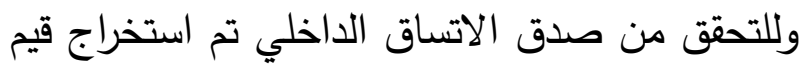
معاملات ارتباط كل فقرة مع الدرجة الكلية للمجال الدال الذي تنتمي اليه، حيث بلغت معامل ارتباط كل فقرة

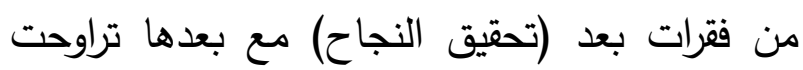

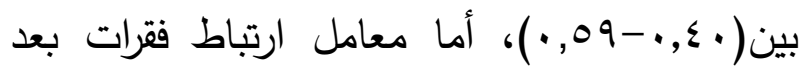

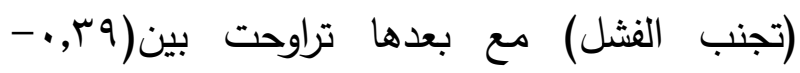

$$
\text { . (•, Or }
$$
ثانياً: الثبات ثبات الإعادة لبعد تجنب الفشل (†人, •) وهي درجة ثبات دالة إحصائياً. كما أن ثبات الاتساق الداخلي لإني

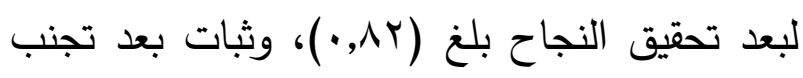

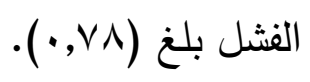

ثانياً: مقياس دافع الإنجاز

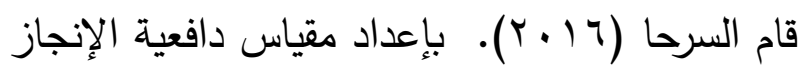

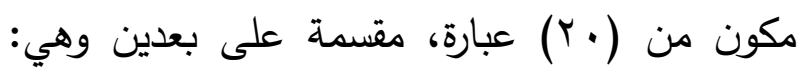

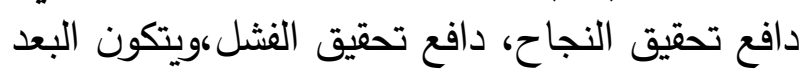

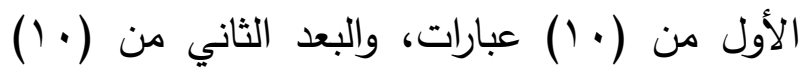

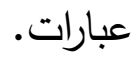

口 تصحيح المقياس 
تم حساب صدق الاتساق الداخلي لدقياس دافع الإنجاز عن طريق عن طريق حساب قيم دعاملات

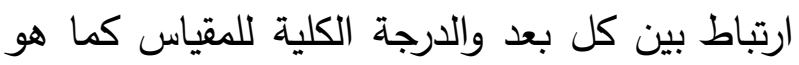

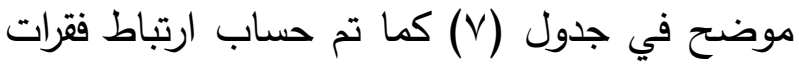

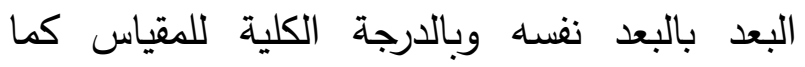

$$
\text { يوضح ذلك جدول (^). }
$$

تم حساب الثبات بطريقة إعادة التطبيق بفاصل زمني

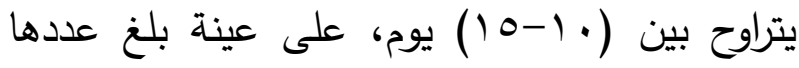
(ro) طالباً وطالبة من طلبة جامعة ال البيت. فكان

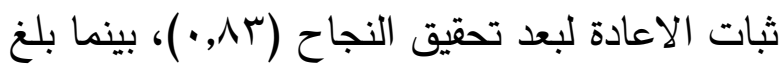
口 صدق وثبات المقياس في الدراسة الحالية

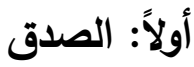

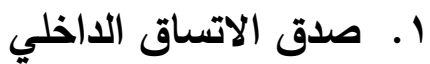

جدول V قيم معاملات الارتباط بين أبعاد مقياس دافع الإنجاز والدرجة الكلية (ن= • ؟)

\begin{tabular}{cr}
\hline الأانول: دافع تحقيق النجاح \\
\hline الأنباد \\
\hline
\end{tabular}

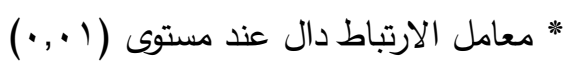

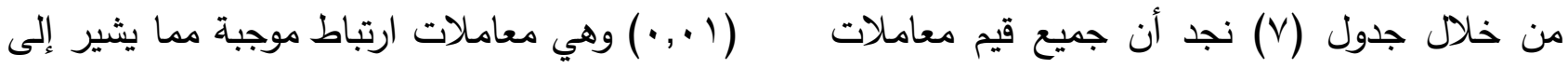

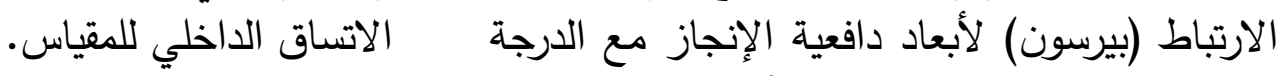

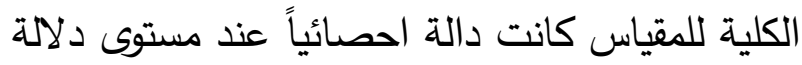

جدول ^ قيم معاملات الارتباط بين درجة كل عبارة والبعد الذي تنتمي إليه واللارجة الكلية لمقياس دافع الإنجاز (ن= . بان)

\begin{tabular}{|c|c|c|c|c|c|}
\hline \multicolumn{6}{|c|}{ الأبعاد } \\
\hline \multicolumn{3}{|c|}{ تجنب الفشل } & \multicolumn{3}{|c|}{ دافع تحقيق النجاح } \\
\hline الارتباط بالدرجة & بالبعد & الفقرة & الارتباط بالدرجة & بالارتباط & الفقرة \\
\hline${ }^{* *}, Y \wedge \varepsilon$ & $", \leqslant Y_{0}$ & $r$ & "*, "ז99 & $" *, \leqslant \wedge 9$ & 1 \\
\hline "r१, & * & $\varepsilon$ & 0,179 & Vדז, " & $r$ \\
\hline ", rOA & ", oor & 7 & ", TIr & " ", r & 。 \\
\hline " & *,074 & $\wedge$ & $* *, \leqslant$, & ",$r \leqslant r$ & v \\
\hline$*, r \circ q$ & $", \leqslant \circ V$ & 1. & $" *, \leqslant \wedge T$ & $", \leq 71$ & 9 \\
\hline "* & " & Ir & * & $", \varepsilon 11$ & 11 \\
\hline${ }^{* *}, \mathrm{r}$ & 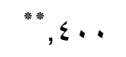 & $1 \varepsilon$ & " r. & אזr," & $\pi$ \\
\hline ", " & " & 17 & . "ז, & " "זro & 10 \\
\hline$", r \circ V$ & $" 0.9$ & 11 & "* , $\{r T$ & $", \leqslant 97$ & IV \\
\hline$* *, \leqslant 91$ & $", V \backslash \wedge$ & $r \cdot$ & $*, r \leqslant q$ & ", 070 & 19 \\
\hline
\end{tabular}

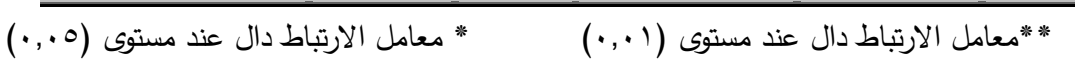




\section{ז. الصدق التمييزي}

تم أخذ الدرجة الكلية لمقياس التتظيم الانفعالي محكاً

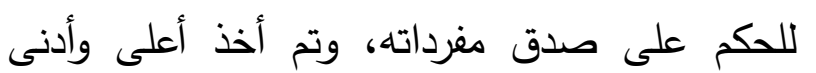

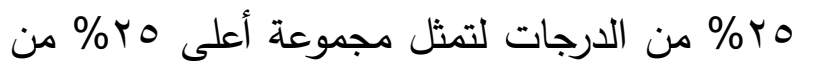

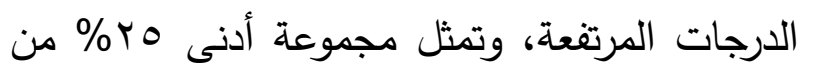
الدرجات المنخفضة في دافعية الانجاز ، وباستخدام

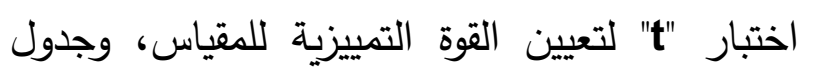

من جدول (^) يتبين أن جميع قيم معاملات الارتباط بين كل فقرة من مقياس دافع الإنجاز والدرجة الكلية

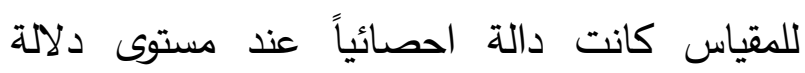

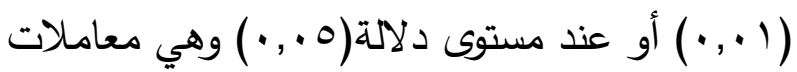
ارتباط موجبة. كما نجد أن قيم معاملات ارتباط

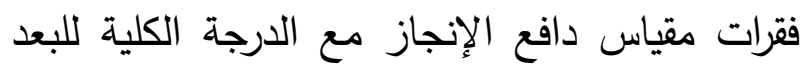

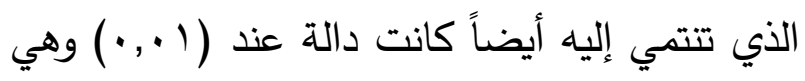
قيم موجبة.

\section{جدول 9}

دلالة الفروق بين متوسطات المجموعات الطرفية (الإباعي الأعلى والإرباعي الأدنى) لمقياس دافع الإنجاز (ن= ؟ )

\begin{tabular}{|c|c|c|c|c|c|c|c|}
\hline \multirow{2}{*}{ مستوى الدلالة } & \multirow{2}{*}{ قيمة (t) } & \multirow{2}{*}{ الدرية } & \multirow{2}{*}{ اللععياري } & \multirow{2}{*}{ الدتوسط } & \multirow{2}{*}{ العينة } & \multirow{2}{*}{ الارباعيات } & \multirow{2}{*}{ المتفير } \\
\hline & & & & & & & \\
\hline 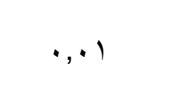 & 9,104 & $7 \varepsilon$ & $\begin{array}{l}\cdot, \text { VYOl } \\
., \text { ANV }\end{array}$ & $\begin{array}{l}\varepsilon, 0 r \\
r, 01\end{array}$ & $\begin{array}{l}r \\
r .\end{array}$ & الإلرباعي الألعلى & جاز \\
\hline
\end{tabular}

يتضح من جدول (9) أن قيمة "ت" للفرق ين متوسطات المجموعات الطرفية (الإرباعي الأعلى - الإرباعي الأدنى) داله إحصائياً

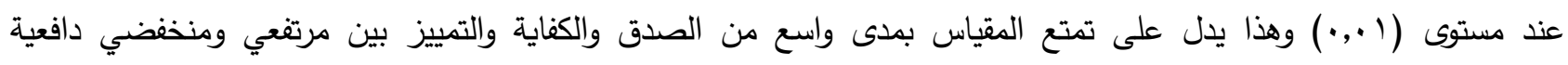
الإنجاز . ثانياً: الثبات تم حساب درجة ثبات مقياس دافعية الانجاز بطريقة الفا كرونباخ والتجزئة النصفية لبانية والنتائج موضحة في جدول (·) (1)

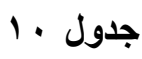

قيم معملات الثبات بطريقتي ألفا كرونباخ والتجزئة النصفية لمقياس دافعية الإنجاز (ن= آ)

\begin{tabular}{|c|c|c|}
\hline \multicolumn{2}{|c|}{ التجزئة النصفية } & معامل \\
\hline (معادلة جتمان) & (سبيرمان براون) & خ \\
\hline$\cdot, 770$ & $\cdot, 770$ & $\cdot, 791$ \\
\hline$\cdot, 7 \wedge 1$ & $\cdot, 79 \leq$ & $\cdot, \vee \backslash 1$ \\
\hline$\cdot, \times 10$ & $\cdot, v \cdot 1$ & , , vo. \\
\hline
\end{tabular}


○. تطبيق أدوات الدراسة على عينة الدراسة متمثلة في طالبات جامعة أم القرى من مختلف الكليات. T. تصحيح الاستمارات وفقاً لطريقة التصحيح

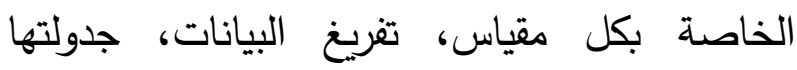

وتحليلها باستخدام الأساليب الإحصائية المناسبة.

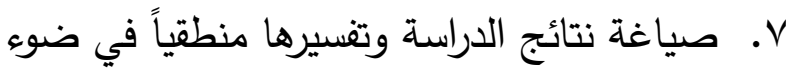
الإطار النظري والدراسات السابقة، واستخلاص لاصه التوصيات والمقترحات المناسبة. 口 الأساليب الإحصائية

المتوسطات الحسابية والانحرافات المعيارية. اختبار (ت) لدلالة الفروق بين المتوسطات.

$$
\begin{aligned}
& \text { معامل ارتباط بيرسون. } \\
& \text { تحليل التباين الأحادي. } \\
& \text { نتائج الدراسة } \\
& \text { نتائج الفرض الأول }
\end{aligned}
$$

للتحقق من الفرض الأول الذي ينص على أنه "توجد

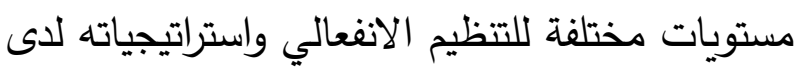
عينة من طالبات جامعة أم القرى" تم حساب لمابل المتوسطات الحسابية والانحرافات المعيارية لدرجات

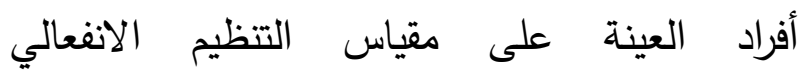
واستراتيجياته على النحو التالي:
من الجدول (• ) نجد ان معاملات الثبات لأبعاد مقياس دافعية الانجاز حسب ألفا كرونباخ تراوحت

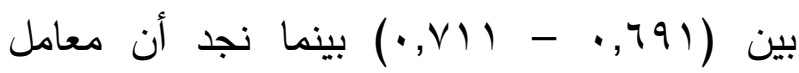

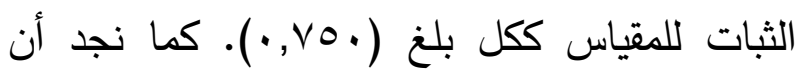
معاملات الثبات بطريقة التجزئة النصفية معادلة سبيرمان براون لأبعاد مقياس دافعية الانجاز تراوحت بطعاته

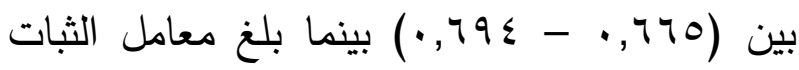

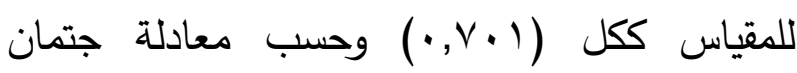
تراوحت معاملات الثبات لأبعاد مقياس دافعية

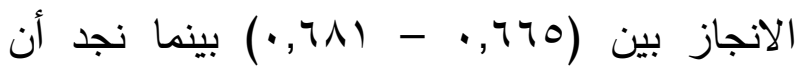

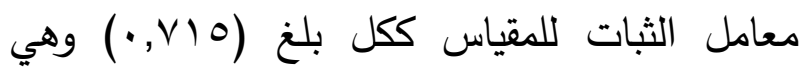

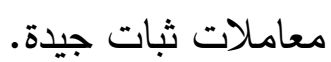
إجراءات الدراسة

للإجابة على التساؤلات والتحقق من الفروض تم القيام بالخطوات التالية: - التهابه 1. كتابة أدبيات الدراسة والدراسات السابقة المتعلقة بالمتغيرات المتمثلة في (التنظيم الانفعالي، دافعية

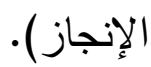
r. تحديد المنهجية المناسبة، وعينة الدراسة وأدواتها.

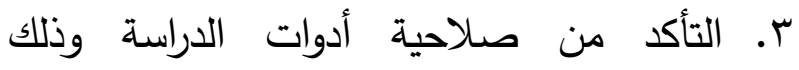
بتطبيقها على عينة استطلاعية مكونة من (†) (7)

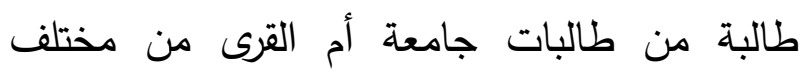
الكليات والأقسام. ـ. اختيار العينة الممثلة لمجتمع الدراسة بالطريقة

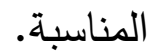


جدول (11)

المتوسطات الحسابية والمرجحة والانحرافات المعيارية لارجات طالبات جامعة أم القرى

\begin{tabular}{|c|c|c|c|}
\hline المستوى & الانحراف & الحسابي & استراتيجيات التنظيم \\
\hline مرتفع & $0, \cdot r$ & 0,01 & اعادة التتييم \\
\hline متوسط & $\varepsilon, 10$ & $\varepsilon, 09$ & الكتمان \\
\hline مرتفع & $\vee, \varepsilon \wedge$ & $0,1 \leq$ & الدرجة الكلية \\
\hline
\end{tabular}

يتبين من الجدول السابق أن مستوى التنظيم والوعي مما يمكنهم من التحكم في انفعالاتهم الانفعالي بشكل عام لاى طالبات جامعة أم القرى وتنظيمها والتقليل من الانفعالات السلبية وتأثيراتها

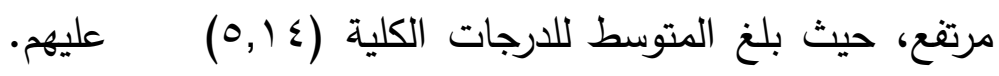

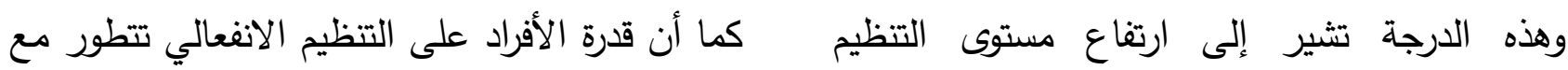

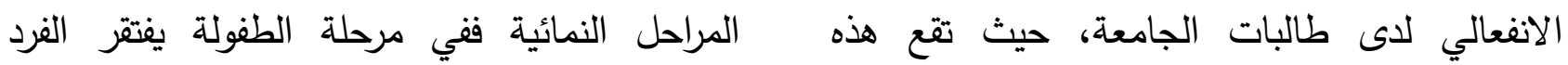

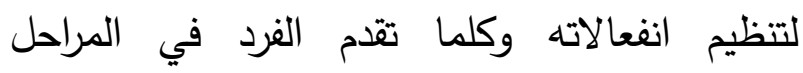

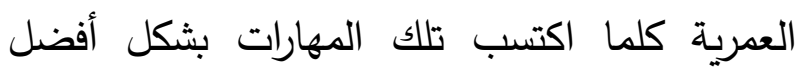
وأوضح وأصبح قادراً على السيطرة على انفعالاته

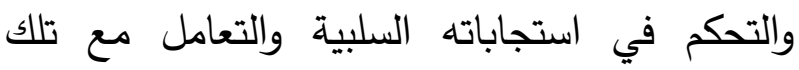
الانفعالات بوعي بحيث لا تؤثر سلباً على أداءه وعلاقاته مع الأفراد. نتائج الفرض الثاني للتحقق من الفرض الثاني والذي ينص على أنه "لائ توجد علاقة ذات دلالة إحصائية بين التنظيم

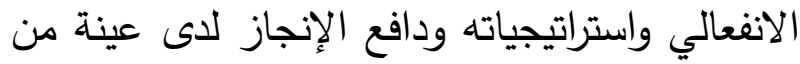
طالبات جامعة أم القرى" تم حساب معامل ارتباط التان بيرسون وذلك لاختبار العلاقة بين درجات أفراد العينة على مقياس التنظيم الانفعالي واستراتيجياته ودافع الإنجاز ، كما يوضح ذلك جدول (r ا):

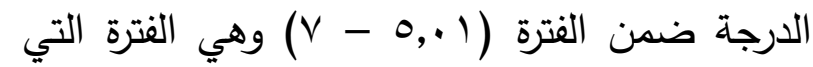
تكون ضمنها درجات التنظيم الانفعالي مرتفعة.

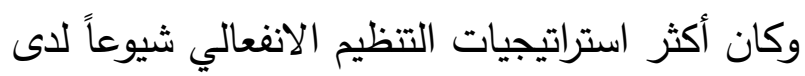

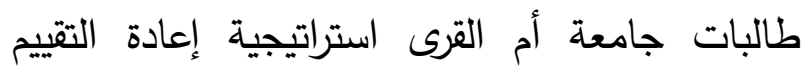
بمتوسط بلغ (0,0) ) يليها استراتيجية الكتمان لدى الى العانيان

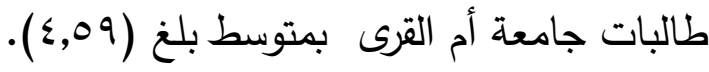
وتتقق تلك النتيجة مع دراسة كلاً من (اسليم، بينما تناقض تلك النتيجة ما توصلت إليها د. VV

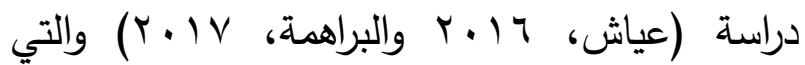
توصلت إلى وجود مستوى جيد من التنظيم الانفعالي

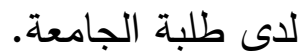
ويمكن تفسير ارتفاع مستوى التنظيم الانفعالي للى الدى طالبات الجامعة إلى طبيعة المرحلة العمرية

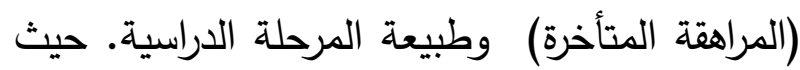
أن طلبة الجامعة على درجة عالية من النضج النجا 
جدول (r)

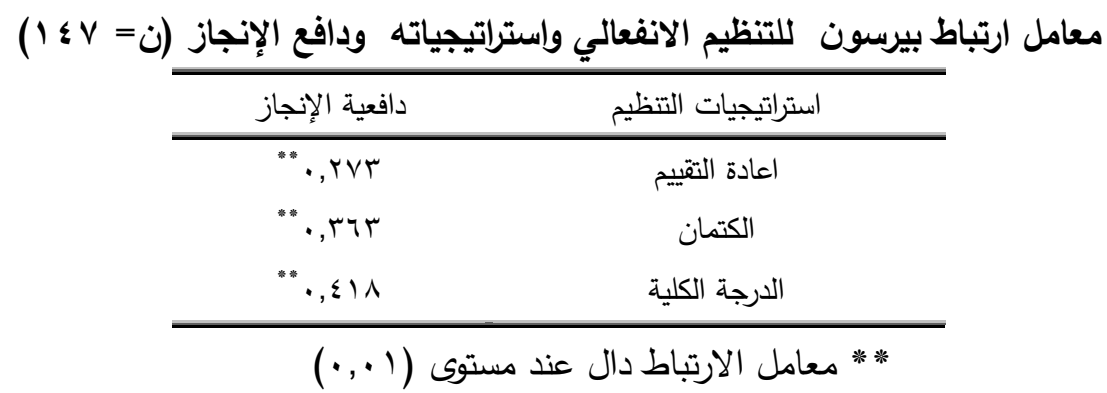

المشكلات النفسية والاجتماعية بانفعال منظم يتناسب مع الموقف الذي يتعرض له الفرد.

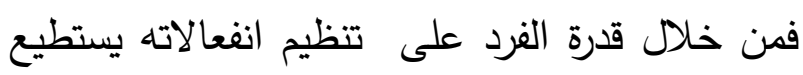
فهم مشاعره والتحكم فيها ومعرفة مخاوفه والتمييز بينها والقدرة على ضبطها مما يساعد على الإنجاز والتغلب على الصعوبات التي تواجهه في أداء المهمات في المجالات المختلفة سواء في المجال الأكاديمي أو غيره من المجالات. نتائج الفرض الثالث للتحقق من الفرض الثالث والذي ينص على أنه "لا توجد فروق ذات دلالة إحصائية بين متوسطات الدرجات الكلية لدافع الإنجاز لدى عينة من طالبات دله داته

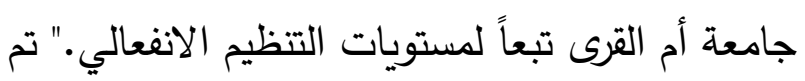
استخدام تحليل التباين للفروق بين المتوسطات في المعات المعات دافع الإنجاز تبعاً لمستويات التنظيم الانفعالي على لهين

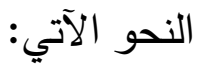

يتبين من جدول (YI) وجود علاقة موجبة دالة

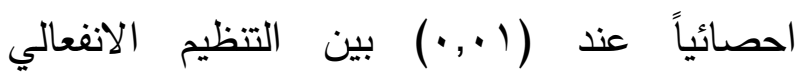

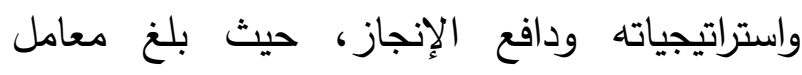
الارتباط بين الدرجة الكلية للتنظيم الانفعالي والدرجة الكلية لدافعية الانجاز (1 الع, • ). ونجد أن أكثر استراتيجيات التتظيم الانفعالي ارتباطاً

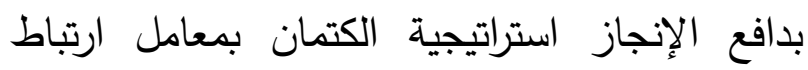

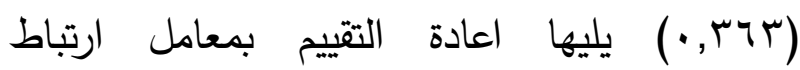
$\cdot(\cdot, r \vee T)$ وتتقق نتيجة الدراسة الحالية مع دراسة كلاً من Decuir-Gunby et al., 2009; Fried \& ) .(Chapman, 2012 وتعتبر تللك العلاقة منطقية وذلك تبعاً للدور المهم الذي يلعبه التنظيم الانفعالي في مجالات الحياة المختلفة، وماله من تأثير كبير في زيادة توافق الفرد النفسي وتوافقه مع المحيطين حوله وتحقيق إنجاز عالي وكفاءة عالية في العمل والقدرة على مواجهة 


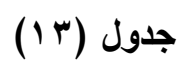

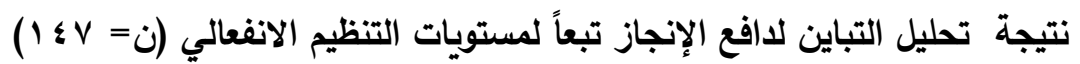

\begin{tabular}{|c|c|c|c|c|c|c|}
\hline الدالة & ف & متوسط المربعات & درجة الحرية & مجموع المربعات & مصدر التباين & الأبعاد \\
\hline \multirow{2}{*}{,$\cdots$} & \multirow{2}{*}{$\lambda, r I r$} & $\mid r Y, \wedge 9 \wedge$ & $r$ & $r \leqslant 0, v 90$ & بين المجموعات & \multirow{3}{*}{ ـافع تحقيق النجاح } \\
\hline & & $1 \leqslant, \vee \wedge 0$ & $1 \leqslant r$ & $r \| \leq, r \mid r$ & داخل المجموعات & \\
\hline \multirow{4}{*}{, $.7 \varepsilon$} & \multirow{4}{*}{$1,9 \vee \vee$} & & $1 \leqslant 0$ & rrq.,..V & الكلي & \\
\hline & & DI,TrT & r & $1 \cdot r, \leq \leq 4$ & بين المجموعات & \multirow{3}{*}{ تجنب الفشل } \\
\hline & & $\mid V, r \cdot \varepsilon$ & $1 \leqslant r$ & $r \leq 7 ., 17 \leq$ & داخل المجموعات & \\
\hline & & & $1 \leqslant 0$ & rotr,TI. & الكلي & \\
\hline \multirow{3}{*}{,$\ldots$} & \multirow{3}{*}{$9,1<9$} & Trצות & r & $T \leq \Lambda, V Y T$ & بين المجموعات & \multirow{3}{*}{ الدرجة الكلية } \\
\hline & & ro,or. & $1 \leqslant r$ & $0 \cdot \Lambda \cdot, \wedge \mu \wedge$ & داخل المجموعات & \\
\hline & & & $1 \leqslant 0$ & OVYq,OTr & الكلي & \\
\hline
\end{tabular}

يتبن من الجدول السابق وجود فروق في دافع بينما لم تسجل درجات بعد تجنب الفشل أي فروقاً

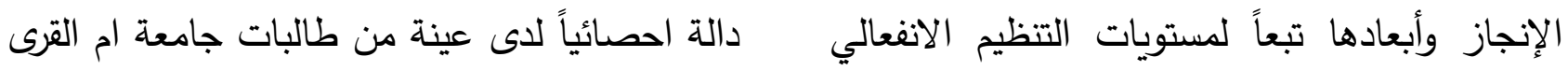

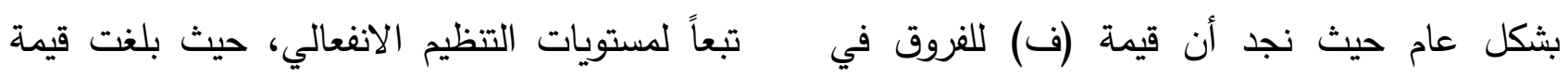

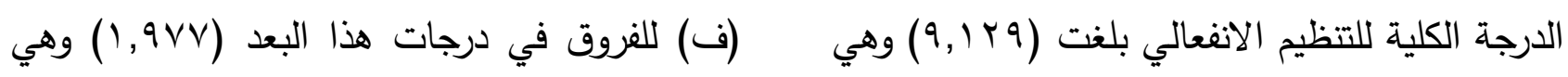

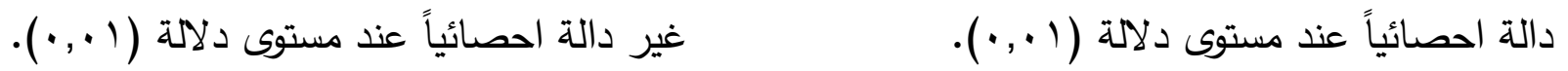

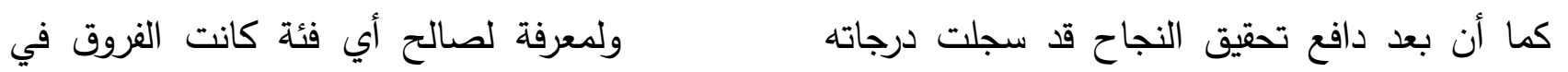
فروقاً دالة احصائياً تبعاً لمستويات التنظيم الانفعالي، ل كل من (بعد دافع تحقيق النجاح - الدرجة الكلية حيث بلغت قيمة (ف) للفروق في درجات هذا البعد لدافعية الإنجاز) تبعاً لمستويات التنظيم الانفعالي

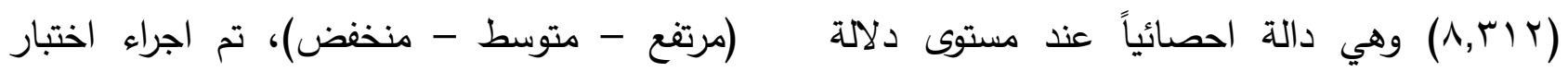

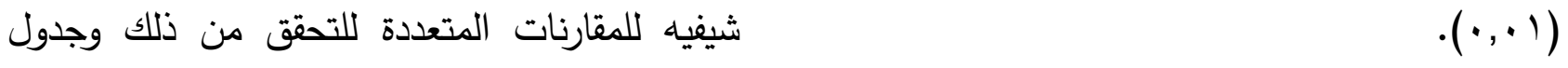

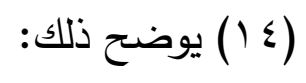




$$
\text { عبير محمد الصبان و سماح عمر السلمي و هبه عبد الحي الأنصاري }
$$

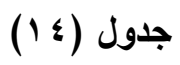

اختبار شيفيه للمقارنات المتعدة (Scheffe) لالالة الفروق في متوسطات (بعد دافع تحقيق النجاح - الارجة الكلية لافع

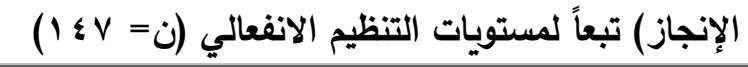

\begin{tabular}{|c|c|c|c|c|}
\hline الدلالة & الفرق في المتوسط & المقارنات & الفئات & الأبعاد \\
\hline $\begin{array}{l}, \cdots \\
, \leqslant \wedge 9\end{array}$ & $\begin{array}{l}r, 09 \wedge 0 . \\
r, V I r \cdot \Lambda\end{array}$ & منخفض متوسط & مرتفع & \\
\hline $\begin{array}{l}\cdots \\
, 999\end{array}$ & $\begin{array}{c}r, 0910 .- \\
, 11 \leqslant 0 \wedge\end{array}$ & منخفض مرتفع & متوسط & دافع تحقيق النجاح \\
\hline $\begin{array}{l}, \& \wedge 9 \\
, 999\end{array}$ & $\begin{array}{l}r, V \backslash r \cdot \Lambda- \\
, \| \leq 0 \Lambda \text { - }\end{array}$ & متوسط مرتفع & منخفض & \\
\hline $\begin{array}{l}, \cdots \\
, V \vee\end{array}$ & 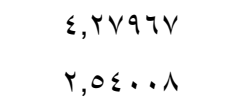 & منخفضط & مرتفع & \\
\hline $\begin{array}{l}, \cdots \\
, \wedge \wedge 0\end{array}$ & 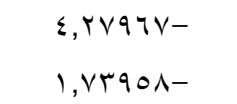 & منخفض مرتفع & متوسط & الدرجة الكلية لدافع الإنجاز \\
\hline $\begin{array}{l}, \mathrm{VV} \cdot \\
, \wedge \wedge O\end{array}$ & $\begin{array}{l}r, 0 \leq \cdots \wedge- \\
1, \vee r 90 \wedge\end{array}$ & مرتفع متوسط & منخفض & \\
\hline
\end{tabular}

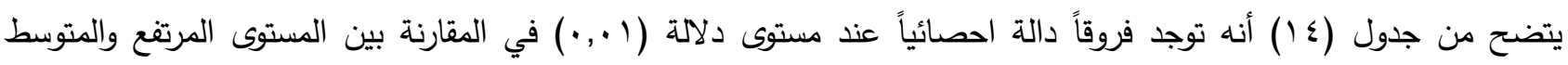

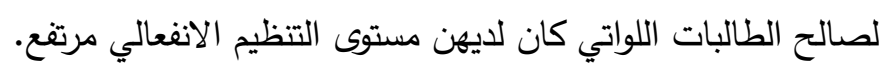

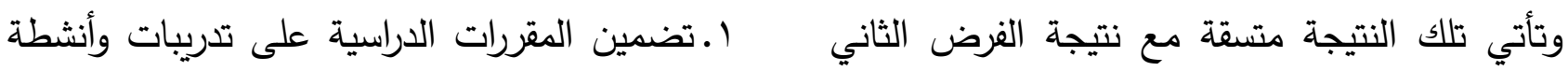
والتي أسفرت عن وجود علاقة موجبة بين التنظيم تسهم في تتمية ورفع مستوى التنظيم الانفعالي.

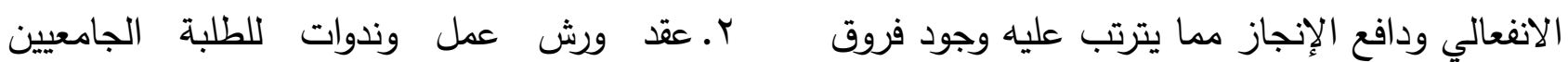
في الدافعية تبعاً لمستويات التنظيم الانفعالي لصالح لتوظيف استراتيجيات التنظيم الانفعالي بفعالية في المستوى المرتفع. ويدل ذلك على أن الطلبة الذين مختلف المواقف الجامعية. لديهم القدرة علي السيطرة على مشاعرهم وانفعالاتهم ب.تقديم دورات تدريبية في استراتيجيات التنظيم وتخلصهم من الانفعالات السلبية اثناء تفاعلهم الانفعالي للقائمين على العملية التعليمية من معلمين يكونون أيضاً لديهم الرغبة في إنجاز مهمات صعبة ومدراء وأساتذة.

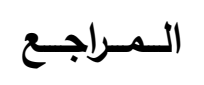

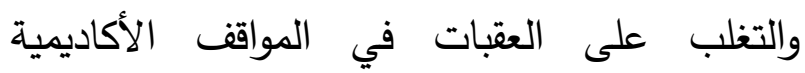

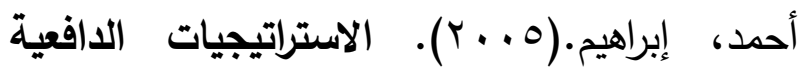
والدراسية. للتعلم وعلاقتها بمستوى الأكاء والمناخ التعليمي ح توصيات الدراسة 


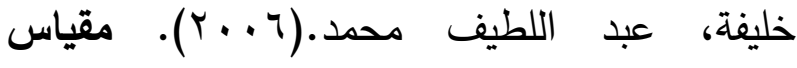
الدافعية للإنجاز. القاهرة: دار غربب للطباعة

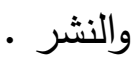

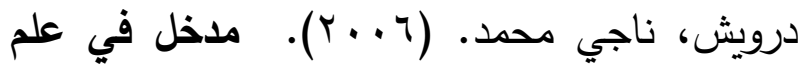
النفس وتطبيقاته التربوية. د.ن.

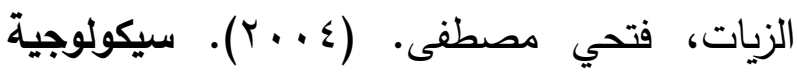
التعلم بين المنظور الارتباطي والمنظور المعرفي. سلسلة علم النفس المعرفي (Y). القاهرة: دار النشر لإني

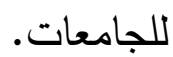

السرحا، محمد ذياب. (7) (ب). الكفاءة الذاتية ودافعية الإنجاز والتعلم المنظم ذاتيا كمتنبئات بالتسويف الأكاديمي لاى طلبة جامعة ال البيت. رسالة دكتوراه غير منشورة. جامعة اليرموك، الأردن.

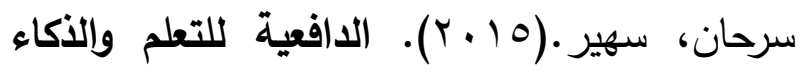
الانفعالي وعلاقتهما بالتحصيل الدراسي لاى طلى طلبة

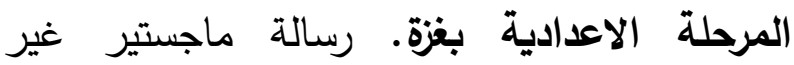
منشورة. جامعة الازهر ، غزة. السيد، عبد المنعم. (r ( • r). الاسترتيجيات المعرفية

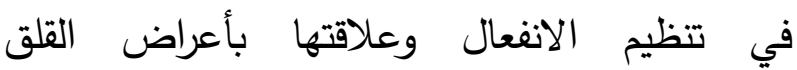
والاكتئاب لدى المراهقين والراشدين. مجلة التربية

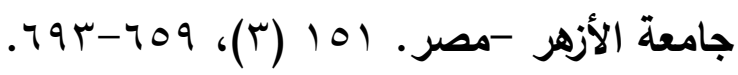
الضبع، فتحي، وشلبي، يوسف. (10 (ب). الاستراتيجيات المعرفية لتنظيم الانفعال كمتغير وسيط بين الكف المعرفي والأعراض الاكتئابية لدى الدى لهنيل طلاب الجامعة. مجلة كلية التربية- جامعة

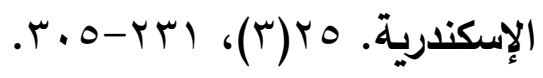

والنوع لاى طلاب المرحلة الثانوية. رسالة ماجستير غير منشورة، جامعة المنصورة

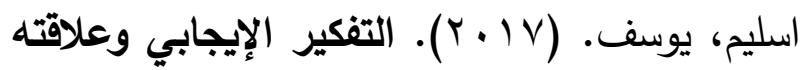
بالتنظيم الانفعالي لاى عينة من خريجي الجامعات الفلسطينية. رسالة ماجستير، الجامعة الإسلامية، فلسطين. باهي، مصطفى حسين، و شلبي، أمينة. (991 (1). الدافعية نظريات و تطبيقات. القاهرة: مركز الكتاب ·لنشر

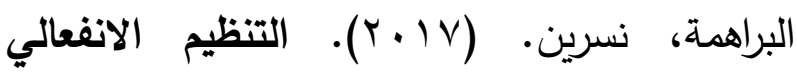
وعلاقته بقلق الاختبار لاى طلبة جامعة اليرموك.

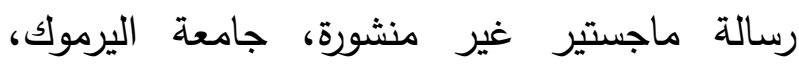
الأردن. بقوش، زينب. (T ا • ب). الاتزان الانفعالي وعلاقته

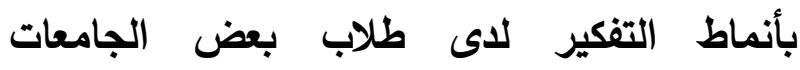
السوادنية. رسالة ماجستير غير منشورة، جامعة أم الماطير

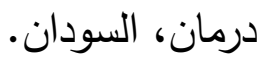

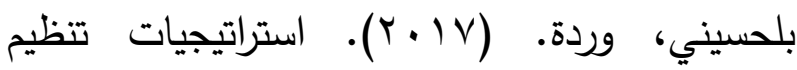

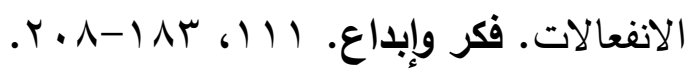
جولمان، دانييل. ( . . . ب). الذكاء العاطفي، (ترجمة ليلى الجبالي). الكويت: مطابع الوطن.

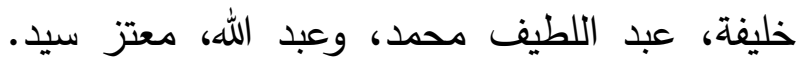

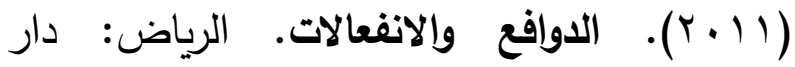

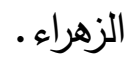

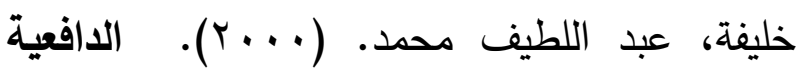
للإنجاز. القاهرة: دار غريب للطباعة والنشر. 


$$
\text { عبير محمد الصبان و سماح عمر السلمي و هبه عبد الحي الأنصاري }
$$

سيكومترية كلينيكية. دراسات عربية في التربية و

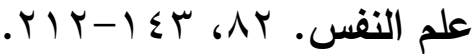

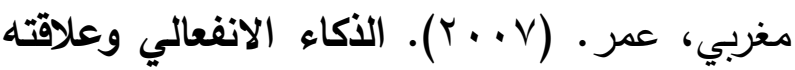
بالكفاءة المهنية لاى عينة من معلمي المرحلة الثانوية في مدينة مكة المكرمة. رسالة ماجستير غير منشورة، جامعة أم القرى.

منصور، عبد المجيد سيد، التويجري، محمد عبد المحسن، و الفقي، إسماعيل محمد. (0. ㄷ). علم النفس التربوي. ط. ع. الرياض: مكتبة العبيكان. موراي، إدوارد (911 (1). الادفعية والانفعال. ترجمة أحمد عبد العزيز سلامة. القاهرة: دار الشروق.

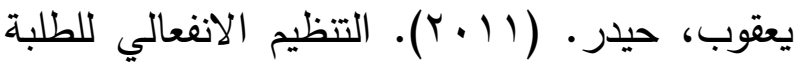
المتميزين في محافظة ديالي. المؤتمر العلمي العربي

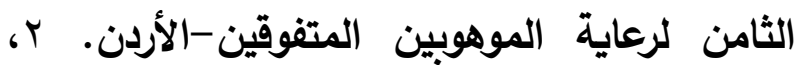
. $₹ \vee \neg-\varepsilon \leqslant 9$

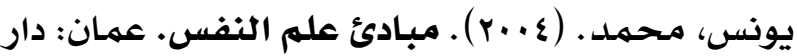
الشروق للطباعة والنشر والتوزيع.

Al, Badareen, G. (2016). Cognitive emotion regulation strategies as predictors of academic achievement among University Students. Journal of Educational and Psychological Studies.10 (4), 680-686.

Albert, T. (2005). Dictionary of Psychology. New York: American Publisher.

Alen, P. (2005). Social Psychology. Toronto: Toronto press.

Boss, T., Pontier, M., Treur, J. (2007). A Dynamical system modelling approach to Gross' model of emotion regulation.Vrije University Amsterdam.
عبد الخالق، أحمد، والنيال، مايسة. (1991). الدافع للإنجاز وعلاقته بالقلق والانبساط. دراسات نفسية-

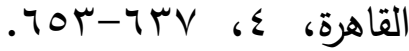

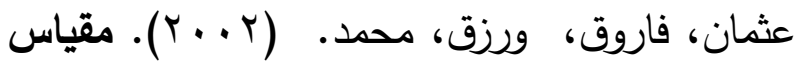
الأكاء الانفعالي مفهومه وقياسه. القاهرة: دار

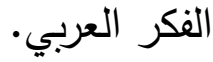
عياش، ليث. (T 1 • r). التنظيم الانفعالي لدى طلبة الجامعة. مجلة كلية التربية الأساسية الجامعة

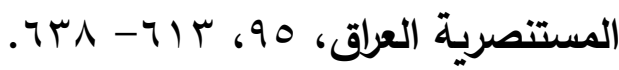
الكناني، ممدوح عبد المنعم، والكندري، أحمد محمد. (1994). سيكولوجية التعلم وأنماط التعليم. الكويت: مكتبة الفتح للنشر والتوزيع. محمد، محمد جاسم. (؟ . . ץ). علم النفس التربوي وتطبيقاته. عمان: مكتبة دار الثقافة للنشر و و التوزيح.

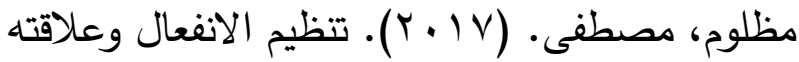
بالأليكسيثيميا لاى عينة من طلاب الجامعة: دراسة

Cisler, J. \& Olatunji, B. (2012). Emotion regulation and anxiety disorders. Current Psychiatry Reports. 14, 183-187.

Cisler, J., Olatunji, B., Feldner, M., \& Forsyth, J. (2010). Emotion Regulation and the Anxiety Disorders: An Integrative Review. J Psychopathol Behav Assess. 32(1), 68-82. DeCuir-Gunby, J., Aultman, L., Schutz, A. (2009). Investigating transactions among motives, emotional regulation related to testing, and test emotions. Journal of Experimental Education. 77, 409-436. Dora, A. (2012). The contribution of Selfcontrolm Emotion Regulation, Rumination, and Gender to Test Anxiety of University 
Students. A thesis Submitted to the Graduate School of Social Scienes of Middle East Technical University, Turkey.

Fried, L., \& Chapman, E. (2012). An investigation into the capacity of student motivation and emotion regulation strategies to predict engagement and resilience in the middle school classroom. Australian Educational Researcher. 39(3), 295-311.

Garnefski, N., \& Kraaij, V. (2007). The cognitive emotion regulation questionnaire psychometric features and prospective relationships with depression and anxiety in adults. European Journal of Psychological Assessment. 23(3), 141-149.

Gratz, K., \& Roemer, L. (2004). Multidimensional assessment of emotion regulation and dysregulation: Development, factor structure, and initial validation of the difficulties in emotion regulationscale. Journal of Psychopathology and Behavioral Assessment. (26)1, 41-54.

Gross, J. (1998). The Emerging field of emotion eegulation: An integrative review. Review of General Psychology. 2(3), 271299.

Gross, J. (1999). Emotion regulation: Past, present, future cognition and emotion. Cognition an Emotion.13(5), p. 551-573.

Gross, J. (2002). Emotion regulation affective, cognitive, and social consequences. Psychophysiology. 39(3), 281-291.

Gross, J. (2007). Regulation of emotion, Handbook of emotion. New York: Guilford Press.

Gross, J., \& John, O. (2003). Individual differences in two emotion regulation processes: Implications for affect, relationships, and well-being. Journal of Personality and Social Psychology. 85, 348362.

Gross, J., Levenson, R. (1993). Emotional Suppression: Physiology, self-report, and expressive behavior. Journal of Personality and Social Psychology. 64(6), 970-986

Han, S. (2009). Emotion regulation, coping, and attachment in bingeing behaviors. Unpublished Ph. D. Thesis, Purdue University. Jazaieri, H., Morrison, A., Goldin, P., \& Gross, J, (2015). The role of emotion and emotion regulation in social anxiety disorder. Current psychiatry reports. 17(1), 531-540 Koole, S., Van Dillen, L., \& Sheppes,G. (2010). The self-regulation of emotion. New York: Guilford Press.

Mayer, J., \& Salovey, P. (1995). Emotional intelligence and the construction and regulation of feelings. Applied and Preventative Psychology. 4, 197 - 208.

Omran, M.(2011). Relationships between cognitive emotion regulation strategies with depression and anxiety. Open Journal of Psychiatry.1, 106- 109.

Putnam, K. \& silk, K. (2005). Emotion dysregulation and the development of borderline personality disorder. Development and psychopalthology. 17, 899 - 925.

Saarni, C. (1999). The development of emotional competence. New York: The Guilford press.

Som'eh, S., Aghdam, J, \& Nosort, H.(2015). The Role of the Strategis of Emotion Regulation in predicting Test Anxiety. Applied Research Educational psychology. 2(1)3, p. 29-40.

Vail, p. (2005). Learning as a way of being : strategies for survival in a world of permanent white water. San Francisco : Jossey-Bass.

Vitello- Cicciu, J. (2003). Innovative leadership through emotional intelligence emotional intelligence. Nursing Management. 34(10), p. 28-33. 


\title{
Emotional Regulation and its Relation to Achievement Motivation in Sample of Students at Umm Al- Qura University
}

\begin{abstract}
Abeer Alsabban, Samah Alsulami, Hiba Al-Ansari
Abstract. the present study aims to reveal the level of emotional regulation and its strategies in sample of students at Umm Al- Qura University. Also, It aims to recognize the relationship between emotional regulation and its strategies and achievement motivation, and reveal the differences in achievement motivation according to the levels of emotional regulation. The sample consisted of (147) students at Umm al-Qura University from various specialties, have applied the emotional regulation scale of Gross \& John (2003), the achievement motivation scale of Al- Sarha (2016). The study's results indicated that there is average level of emotional regulation in sample and the most common strategy is reappraisal then suppression. The results also showed that there is a positive statistically significant relationship between emotional regulation and its strategies and achievement motivation. Also, There are statistically significant differences in achievement motivation and its dimensions according to the levels of emotional regulation in favor of high level. According to the results the study recommended a number of recommendations.
\end{abstract}

